\title{
Impacto de los esquemas de subcontratación en la expansión del valor agregado y la productividad en la economía de México y sus regiones
}

Fernando Camargo Pérez*

\section{RESUMEN}

El factor trabajo se encuentra en un círculo deforme en México. Ante la baja contribución en la productividad total de los factores y la aparente presión que ejerce sobre la inflación, se ha legitimado y justificado el pago de bajos salarios para hacer competitivas a las empresas; sólo que esa baja contribución no está vinculada a una caída en su productividad, ya que el ritmo se ha mantenido favorablemente trás la crisis financiera de 2009, al tiempo que los costos unitarios de la mano de obra han disminuido. Es válido, por lo tanto, plantear la viabilidad de un mayor crecimiento económico y margen de productividad a partir de cambios en la política laboral vigente. Esto es factible si se amplían los espacios al trabajo subordinado a una razón social que produce bienes y presta servicios directamente, en detrimento del régimen de subcontratación (outsourcing) que está fuertemente asociado a la informalidad; esto conlleva la recuperación de salarios y prestaciones del trabajo remunerado.

Palabras clave: valor agregado, productividad, trabajadores remunerados, subcontratación, costo unitario de la mano de obra.

Clasificación JEL: J31, J53, O14, O18, R11 y R12.

\footnotetext{
Consultor independiente, México. Correo electrónico: fernandocamargoperez@gmail.com. El autor agradece a José Luis Sosa Hernández, Rosa Azálea Canales García, Wendy Ovando Aldana y Ángel Mauricio Reyes Terrón los invaluables comentarios al documento preliminar, y a Elisa Escamilla Ceballos por la traducción del resumen.
} 


\section{ABStRACT}

Impact of outsourcing schemes on the expansion of value added and productivity in the economy of Mexico and its regions

In Mexico, the labor factor is in a deformed circle. Given the low contribution to total factor productivity and the apparent pressure on inflation, the payment of low wages has been legitimized and justified in order to make the companies competitive; only this low contribution is not linked to a drop in productivity, since the pace has been maintained favorably after the financial crisis of 2009, while the unit labor costs have decreased. It is valid, therefore, to propose the viability of greater economic growth and productivity margin based on changes in current labor policy. This is feasible if spaces are extended to subordinated work to a company that produces directly goods and provides services, to the detriment of the outsourcing regime that is strongly associated with informality, this entails the recovery of wages and benefits from paid work.

Keywords: added value, productivity, paid workers, outsourcing, unit cost of labor.

JEL Classification: J31, J53, O14, O18, R11 y R12.

\section{INTRODUCCIÓN}

El bajo desempeño de la economía nacional y de las entidades federativas se puede atribuir al desplazamiento del valor agregado (VA) ante el consumo intermedio (CI), ambos conceptos constituyen el valor del producto final (producción bruta total, PBT), de la siguiente forma: $\mathrm{PBT}=\mathrm{VA}+\mathrm{CI}$.

Como creador de valor, junto con el capital (K), el factor trabajo (L) es el que ha recibido el mayor impacto, debido al deterioro del salario y sus prestaciones, y la presencia cada vez mayor de los esquemas de subcontratación, cuya contribución en los procesos de producción se registra como parte del CI y no del va. El saldo es que la productividad total de los factores (PTF) de la economía nacional es insuficientemente competitiva, porque la contribución de cada factor (por el lado del va: $\mathrm{K}$ y L) es menor ante los insumos utilizados en la producción: energía (E), materias primas (M) y servicios (s), de los cuales se deriva la siguiente identidad: 
$\mathrm{PTF}=$ Producción - Contribución $(\mathrm{K}+\mathrm{L}+\mathrm{E}+\mathrm{M}+\mathrm{S})$.

En este esquema se observan aspectos adversos al factor trabajo porque ante la caída de su contribución en la productividad total y la aparente presión que ejerce sobre la inflación, se ha legitimado y justificado el pago de bajos salarios para hacer competitivas a las empresas; solo que la tendencia a la baja en la contribución no está vinculada a una caída en su productividad, ya que el ritmo se ha mantenido favorable tras la crisis financiera de 2009, a la vez que los costos unitarios de la mano de obra (CUMO) han disminuido.

Es válido, por lo tanto, plantear si es viable un mayor crecimiento económico y margen de productividad a partir de cambios en la política laboral vigente en México y sus regiones. A manera de hipótesis la respuesta es favorable, siempre que se considere ampliar los espacios para el trabajo remunerado frente al régimen de subcontratación, el cual está fuertemente asociado a la informalidad; esto conlleva la recuperación de salarios y prestaciones, particularmente, del trabajador remunerado. Si la acción gubernamental, en sus diferentes ámbitos, se enfoca en identificar el grado de deterioro de las condiciones laborales, y delinea políticas y estrategias para enfrentan problemas adyacentes en esta materia, es posible que la economía en su conjunto geste un escenario macroeconómico adecuado tendiente a fortalecer la competitividad, a la vez de mejorar los estándares de bienestar social.

El objetivo del presente artículo es identificar si el mercado laboral de los trabajadores remunerados en México y sus regiones pueden modificarse sin restar competitividad a las empresas y presionar el índice de precios, para ello se proponen tres partes. La primera describe los elementos que constituyen el valor agregado y la influencia de los factores de la producción en la productividad total en México; en particular analiza la diferencia entre trabajador remunerado directamente por una razón social y el trabajador subcontratado por terceros, en el que uno contribuye al incremento del valor agregado y otro al consumo intermedio. La segunda analiza la productividad y el costo de la mano de obra remunerada en términos macroeconómicos, bajo los cuales se identifican las posibilidades de mejorar el ingreso de los trabajadores al tiempo que mejora la competitividad con base en la productividad por persona ocupada o por hora trabajada. En la última, se perfila el análisis de la ocupación y el empleo en el ámbito regional. 


\section{LA FORMACIÓN DE VALOR AGREGADO Y SU INCREMENTO (PRODUCTIVIDAD)}

El capital y el trabajo son los factores que dan origen al valor agregado, que se define como el incremento de valor en las fases sucesivas de la producción de bienes y servicios, sea de forma intermedia o final (SPP, 1981: 16 y 31). Para calcular el va se resta al valor del producto final (producción bruta total, PBT) el de los bienes y servicios de consumo intermedio (CI):

$$
\mathrm{PBT}-\mathrm{CI}=\mathrm{VA}
$$

que equivale a:

$$
\mathrm{PBT}=\mathrm{VA}+\mathrm{CI}
$$

La aportación de capital $\mathrm{K}$ al vA se mide a través de la depreciación de la formación bruta de capital fijo (maquinaria y equipo) y el uso de tecnologías de la información y comunicación (TIC); la del trabajo refiere las remuneraciones pagadas directamente por la razón social a los trabajadores, mediante salarios y prestaciones (INEGI, 2014a: 9-10, 2015a: 9 y 13 y 2017a: $15-16$ ).

El CI, por otro lado, incluye los insumos de origen interno o importado necesarios para la producción, como todos aquéllos servicios que proporcionan las condiciones propicias para llevar a cabo la producción. Está conformado por: 1) materiales utilizados para la prestación de servicios, las materias primas y auxiliares consumidas, como envases y empaques; 2) consumo de energéticos: como combustibles, lubricantes y energía eléctrica; y 3) servicios, que contempla gastos por renta y alquiler de bienes muebles e inmuebles, contratación de servicios profesionales, científicos y técnicos, suministro de personal por terceros, pagos por maquila de bienes, publicidad, servicios de comunicación, primas de seguros de bienes y servicios, pagos por regalías, reparaciones y refacciones para mantenimiento corriente, viáticos y pasajes, y otros gastos por consumo de bienes y servicios (INEGI, 2015a: 71 y 2017b: 13).

La comparación del va con el CI puede delimitar en primer plano el grado de integración de las estructuras en el ámbito sectorial o 
regional $^{1}$; reflejar, además, la racionalidad con que se utilizan los factores para producir un bien o prestar un servicio. El cambio en la dimensión del producto $(\mathrm{Y})^{2}$ al variar la forma de combinar los factores empleados es lo que se denomina productividad total de los factores, que se mide como el residuo que resulta de descontar a la producción los factores utilizados en el proceso (INEGI, 2017a: 22). Para ello se utiliza el modelo KLEMS (INEGI, 2014a y 2017a), que está basado en una función de producción de la forma:

$$
(\mathrm{Y})=f(\mathrm{~K}, \mathrm{~L}, \mathrm{E}, \mathrm{M}, \mathrm{S})
$$

El comportamiento en el producto se puede expresar como:

$$
\Delta \mathrm{Y}=\alpha \Delta \mathrm{K}+\beta \Delta \mathrm{L}+\gamma \Delta \mathrm{E}+\varepsilon \Delta \mathrm{M}+\theta \Delta \mathrm{S}+\Delta \mathrm{A}
$$

Donde las letras K, L, E, M, S, significan capital, trabajo, energía, materiales y servicios respectivamente; el símbolo $\Delta$ significa incremento. Las letras griegas $\alpha, \beta, \gamma, \varepsilon, \theta$, son las participaciones de los factores dentro del valor de producción (Y); la letra A es el indicador de la PTF.

La ecuación de productividad del modelo KLEMS es:

$$
\mathrm{PTF}=(\mathrm{Y})-(\mathrm{K}+\mathrm{L}+\mathrm{E}+\mathrm{M}+\mathrm{S})
$$

Con base en este modelo, se evalúa cuál ha sido el comportamiento de los factores de la producción.

1 La evaluación del grado de integración se da a partir de la relación de valor agregado (VA) con respecto al valor del producto final (VA/PBT). Entre mayor es la participación de VA frente al consumo intermedio (CI) mayor es el nivel de eficiencia. Algunos criterios para evaluar la eficiencia son: 1) Alta contribución de VA: Participación entre 100.0 y 66.6 por ciento. La alta contribución radica en que dos terceras partes del producto final es valor agregado. 2) Contribución moderada de VA. Aportación entre 66.5 y 50.1 por ciento. El VA en su parte más baja es mayor al CI. 3) Equilibrio: participación en partes iguales del VA y CI en el valor del producto final. 4) Dependencia moderada de CI: Participación del VA entre 49.9 y $39.9 \%$ en el bien final. 5) Alta dependencia de CI: Participación del VA entre 39.8 y $0.0 \%$, que implica que al menos 6 de cada 10 pesos del producto final, son insumos (Camargo, 2019:17).

2 La función de producción Y se refiere al producto interno bruto (PIB); incluye el valor agregado en valores básicos, el excedente de explotación (que son los pagos a la mano de obra no asalariada, los intereses, regalías y utilidades), las remuneraciones a los empresarios, además de los impuestos indirectos, menos subsidios que las empresas transfieren al gobierno (SPP, 1981a: y 1981b: 14; e INEGI, 2015a: 71 y 2017a: 22). 


\subsection{Productividad total de los factores en la economía mexicana}

Tras un largo periodo, que va de 1991 a 2017, la combinación de los factores de la producción en México muestra una fuerte incapacidad para aumentar la producción y la productividad. Anualmente, en promedio, el producto interno bruto (PIB) se ha incrementado $2.76 \%$, variación que es inferior al $3.10 \%$ que alcanzaron los recursos utilizados en el proceso productivo durante el periodo; el resultado es que la PTF es negativa en 0.34 puntos. De los 27 años que abarca la información, más de la mitad observa saldo deficitario (cuadros 1 y 2). Si se observa por décadas, la de 1991 a 2000 es de crecimiento cero; la de 2001 a 2010 de (-) 0.85 puntos y en lo que va de la tercera, de 2011 a 2017, es de (-) 0.10 puntos. Sólo un periodo quinquenal tuvo crecimiento: de 1996 a 2000 la productividad aumentó en 0.64 puntos, lapso que coincide con el arranque del modelo de exportación de manufacturas que trajo consigo el Tratado de Libre Comercio de América del Norte (TLCAN), y que contribuyó a que el PIB alcanzara su máximo crecimiento, con $6.16 \%$ anual. En cambio, el lustro con menor incremento coincide con el de la crisis financiera internacional: entre 2006 y 2010, la productividad cayó 0.96 puntos, cuando el producto aumentó en $1.49 \%$ anual y el uso de los factores en 2.44 por ciento. 


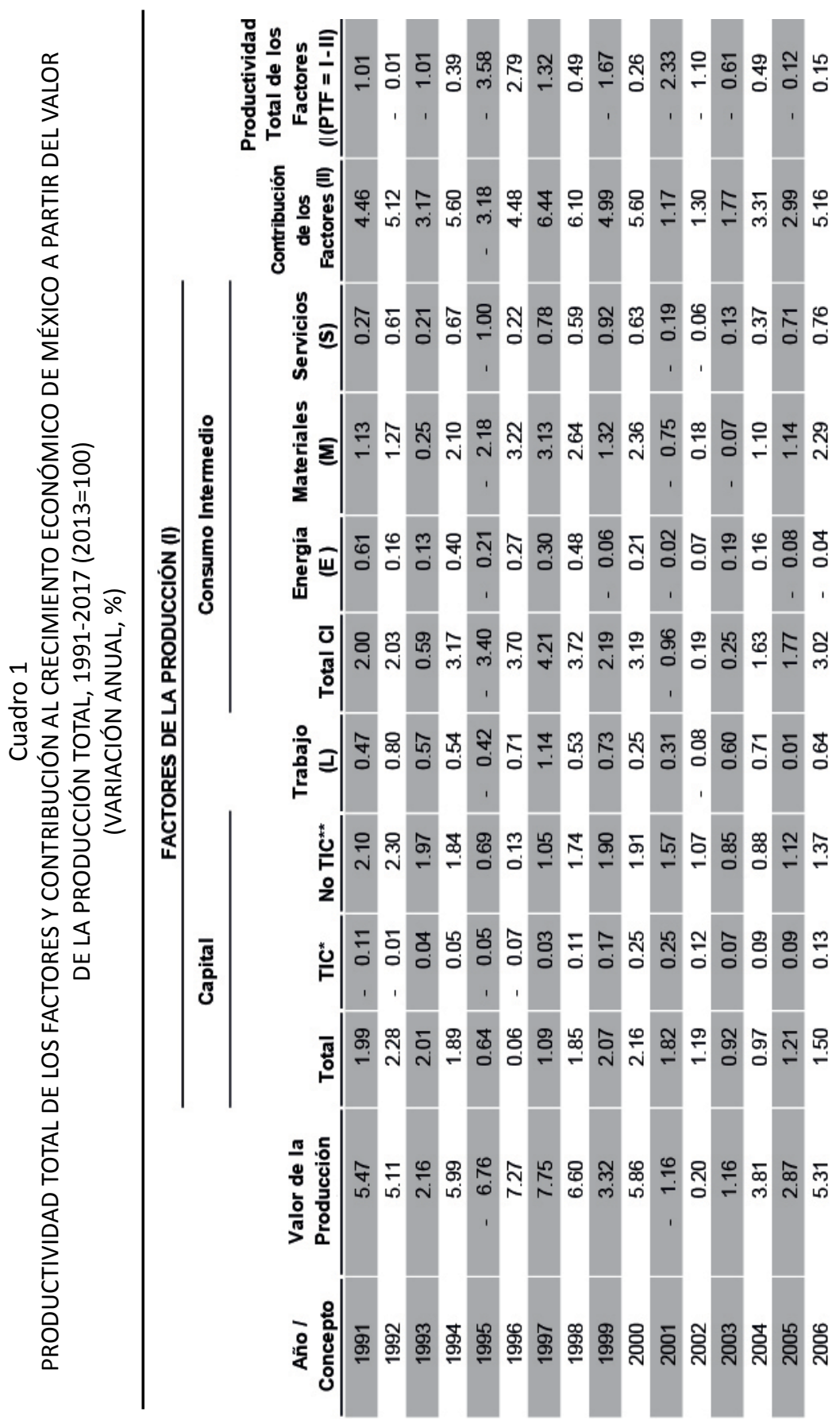




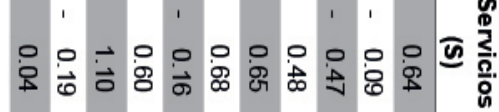

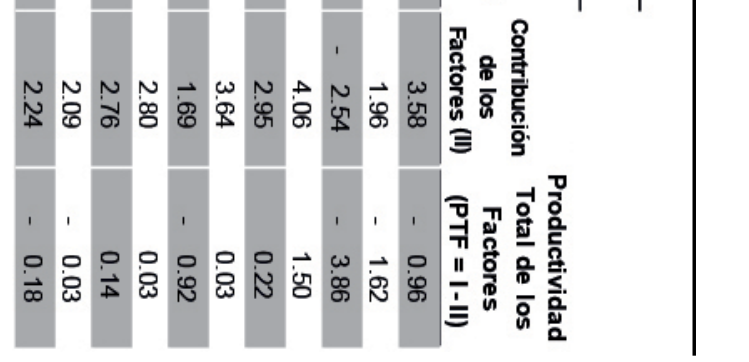




\section{Cuadro 2}

CONTRIBUCIÓN AL CRECIMIENTO DEL PIB DE MÉXICO, 1991-2017

\begin{tabular}{|c|c|c|c|c|c|c|c|c|c|}
\hline & \multirow[t]{2}{*}{ Conceptos } & \multicolumn{4}{|c|}{$\begin{array}{l}\text { CONTRIBUCIÓN AL CRECIMIENTO } \\
\text { (Variación anual promedio, \%) }\end{array}$} & \multicolumn{4}{|c|}{$\begin{array}{c}\text { CONTRIBUCIÓN AL CRECIMIENTO } \\
\text { (Como porcentaje de la variación } \\
\text { anual) }\end{array}$} \\
\hline & & $\begin{array}{l}1991- \\
2017\end{array}$ & $\begin{array}{l}1991- \\
2000\end{array}$ & $\begin{array}{l}2001- \\
2010\end{array}$ & $\begin{array}{l}2011- \\
2017\end{array}$ & $\begin{array}{l}1991- \\
2017\end{array}$ & $\begin{array}{l}1991- \\
2000\end{array}$ & $\begin{array}{l}2001- \\
2010\end{array}$ & $\begin{array}{l}2011- \\
2017\end{array}$ \\
\hline A & $\begin{array}{l}\text { Valor de la Producción } \\
\text { (PIB) }\end{array}$ & 2.76 & 4.28 & 1.43 & 2.49 & - & - & - & 0.00 \\
\hline \multirow{9}{*}{ B (Factores) } & Total de los factores & 3.10 & 4.28 & 2.28 & 2.60 & 100.00 & 100.00 & 100.00 & 100.00 \\
\hline & 1. Capital (K): & 1.43 & 1.60 & 1.33 & 1.31 & 46.03 & 37.50 & 58.52 & 50.43 \\
\hline & $\begin{array}{l}\text { Equipo de cómputo y } \\
\text { comunicaciones }\end{array}$ & 0.09 & 0.04 & 0.14 & 0.10 & 3.03 & 0.95 & 6.17 & 4.00 \\
\hline & Maquinaria y equipo & 1.33 & 1.56 & 1.19 & 1.21 & 42.99 & 36.55 & 52.36 & 46.43 \\
\hline & 2. Trabajo (L) & 0.39 & 0.53 & 0.30 & 0.31 & 12.51 & 12.45 & 13.13 & 11.89 \\
\hline & $\begin{array}{l}\text { 3. Consumo de bienes } \\
\text { y sercicios }\end{array}$ & 1.29 & 2.14 & 0.65 & 0.98 & 41.46 & 50.05 & 28.35 & 37.68 \\
\hline & Energía $(E)$ & 0.03 & 0.23 & -0.02 & -0.18 & 1.00 & 5.35 & -0.67 & -7.13 \\
\hline & Materias primas (M) & 0.92 & 1.52 & 0.43 & 0.77 & 29.82 & 35.60 & 18.95 & 29.83 \\
\hline & Servicios (S) & 0.33 & 0.39 & 0.23 & 0.39 & 10.64 & 9.10 & 10.07 & 14.97 \\
\hline$C=A(-) B$ & $\begin{array}{l}\text { Productividad total de } \\
\text { los factores }\end{array}$ & -0.34 & 0.00 & -0.85 & -0.10 & - & - & - & - \\
\hline
\end{tabular}

Fuente: INEGI (2018). SCNM: Productividad Total de los Factores Modelo KLEMS.

De los factores que conforman el valor agregado, solo el capital (particularmente en su vertiente convencional -maquinaria y equipo), ha tenido un papel preponderante a lo largo de todo el periodo, mientras que los servicios laborales muestran un magro crecimiento, que tiende a profundizarse desde 2013. En casi tres décadas, la contribución del total de los factores al crecimiento económico aumentó 3.10\% anual; el capital contribuyó con 1.43 puntos porcentuales, mismos que equivalen a $46.0 \%$ del total; en cambio, los servicios laborales solo participaron con 0.39 puntos, lo que representa 12.5 por ciento. Esto significa que los restantes 41.5 puntos provienen del consumo de bienes y servicios utilizados para los procesos de producción, los cuales variaron anualmente en 1.3 por ciento. Las materias primas son las de mayor peso con $29.8 \%$ de contribución, seguido de los servicios (donde se incluye la subcontratación) con $10.6 \%$; la otra parte corresponde a los energéticos, con 1.0 por ciento. La conclusión es que prácticamente el factor capital es el que ha sostenido la productividad de la economía mexicana, aun en los puntos más bajos del ciclo económico que corresponden a 1995 y 2009, por lo que es el factor de mayor influencia tanto en valor agregado como en productividad (cuadro A.1 del anexo). Tras la crisis 
financiera internacional, su aportación ha sido primordial para contener el deterioro económico: entre 2011 y 2017 representa la mitad de la contribución total del crecimiento nacional.

Como el modelo KLEMs no define por sí mismo el uso óptimo de los factores, se podría pensar, a manera de hipótesis, que el factor capital es el que ha afectado la productividad total de los factores. No es así, porque en la ecuación de la PTF = PIB - Contribución de los Factores, el producto debe tener un incremento mayor al de la contribución de los factores para que el margen en productividad sea positivo; los únicos factores que generan nuevo valor son el capital y el trabajo; en consecuencia, la racionalidad en la utilización y combinación de los factores debe concentrarse en las variables del consumo intermedio (energía, materiales y servicios), lo que no implica que los factores capital y trabajo queden al margen de una optimización en su uso para producir más con la misma cantidad de factores e insumos, o tengan que disminuir para producir un mismo volumen de producto.

En la economía mexicana, los insumos intermedios son los que han restringido el potencial crecimiento de la producción. El alto costo y el uso ineficiente han inducido la caída de la productividad total. La crisis de 2009 al motivar una mayor racionalidad originó que su contribución se redujera en poco más de 4 puntos porcentuales en los último siete años con respecto al promedio de largo plazo, pero aumentó 9 puntos con relación a la década 2001-2010. La alta ponderación de este factor a lo largo del periodo puede ser reflejo de cierta incapacidad de las estructuras productivas para constituir cadenas de valor para reducir el uso intensivo de materias primas provenientes, sobre todo, del exterior para producir bienes manufactureros (Camargo, 2017: 140-150). A esto se suma el uso desmedido que se ha dado a los servicios de subcontratación de personal (outsourcing) con el propósito de reducir los costos laborales, situación que ha dañado el potencial crecimiento del valor agregado.

En el caso de las materias primas, en la última fase se han mantenido en el promedio de largo plazo, con $29.83 \%$, pero si se compara con lo acontecido en la década anterior, la contribución se ha incrementado en 11 puntos. No es el caso del factor energético, ya que ha favorecido el dinamismo económico y la productividad debido a que rara vez su 
costo rebasa $6.0 \%$ del total, incluso, en años específicos su contribución es negativa, particularmente, entre 2011 y 2017 el promedio es de $-7.13 \%$, como consecuencia de la caída de los precios internacionales de productos petrolíferos.

En cambio, los servicios han tendido a incrementar su contribución incluso por encima del factor trabajo. Entre 2011-2017, su aportación es mayor en 3 puntos: $14.97 \%$ contra $11.89 \%$, situación que coloca a este último en una situación de fragilidad económica y social, ya que su magra contribución es el reflejo de la caída real de los salarios y las prestaciones, que son los que incrementan el valor de la producción e influyen en la productividad. La fuerte presencia de los servicios expresa cómo la subcontratación ha sido utilizada para mejorar la competitividad de las empresas por la vía de bajos salarios y prestaciones. Visto así, la competencia entre trabajo remunerado y subcontratado es un punto neurálgico para el crecimiento productivo de México.

\subsection{Características de las variables de ocupación y empleo}

La influencia de los estratos que conforman el personal ocupado depende de la forma en que están incorporados en una relación laboral. En el mercado concurren dos grupos, cada uno contribuye en el proceso de producción de manera distinta. El primero integra al personal subordinado a una razón social, que se divide en propietarios, familiares y otros trabajadores sin remuneración, además de los trabajadores remunerados, que pueden ser de planta o eventual (INEGI, 2015a: 9-13). El segundo refiere al personal que no depende directamente de la razón social, particularmente al que es suministrado por un tercero a través del régimen de subcontratación u outsourcing, además de servicios profesionales, científicos y técnicos, y el personal contratado por honorarios o comisiones sin sueldo base, conocido comúnmente como trabajador independiente.

El capital y el trabajo remunerado constituyen los factores básicos de la producción. Ambos tienen la cualidad de crear valor e influir en su expansión cuando se combinan y utilizan en forma eficiente los insumos necesarios para producir una cantidad determinada de bienes y servicios. Este rendimiento, como se ha mencionado, es la productividad, la cual sustenta la competitividad sectorial y regional de las empresas para competir en los mercados en forma sostenida a largo plazo (Porter, 1991: 26-29). 
La formación de valor agregado por parte del empleo remunerado (formal e informal) proviene de los salarios y prestaciones que pagan las unidades económicas para producir un bien o servicio de forma directa (INEGI, 2014b: 9). Aquí se excluye los pagos a terceros por el suministro de personal, de comisiones y honorarios para el personal que no recibe un sueldo base, y de honorarios por servicios profesionales contratados de forma infrecuente (INEGI-AMIA, 2016: 9). Su intervención en la expansión del producto por unidad de trabajo o jornada laboral da lugar a la productividad laboral ${ }^{3}$, la cual expresa el rendimiento del capital humano e intelectual de acuerdo a sus características. La portabilidad de talento, habilidades y capacidades adquiridas a través de la educación, capacitación y experiencia, son elementos que constituyen el capital intelectual o intangible que aporta el trabajador para sostener las ventajas competitivas de las empresas (Sánchez, 2007: 98-100).

El problema que se plantea cuando el capital humano es contratado en forma indirecta a través del régimen de subcontratación es que su contribución en el proceso productivo no es contabilizada en las Cuentas nacionales como valor agregado, sino parte del consumo intermedio: como un costo que proviene de la adquisición de un servicio; de tal manera, en el momento en que se dimensiona la productividad laboral, su aportación queda al margen (INEGI, 2014b: 12).

De manera más amplia, la productividad laboral relaciona la producción obtenida o vendida y la cantidad de trabajo incorporado en el proceso productivo, sea mediante el número de horas o el número de trabajadores.

La relación permite evaluar el rendimiento de una unidad económica en un periodo determinado. El aumento de la productividad ocurre cuando:

a. El volumen de producción o de ventas se eleva en un porcentaje mayor que el factor trabajo.

b. La cantidad producida o vendida disminuye, pero las unidades de trabajo bajan a un ritmo superior.

c. La cantidad del insumo laboral utilizado no varía y se incrementa el volumen de lo producido o vendido.

d. El margen de producción o ventas se sostiene al aplicar menos unidades de trabajo.

En cambio, la productividad disminuye cuando:

a. La producción o ventas decrecen al mismo tiempo que el factor trabajo aumenta, se mantiene constante o disminuye con menor intensidad.

b. La producción o ventas aumentan y el trabajo también lo hace, pero en mayor medida (INEGI, 2016a: 1). 
- Las repercusiones de orden económico y social que se derivan de esta situación va más allá del carácter meramente técnico y de contabilidad, por lo siguiente: Si en el transcurso del tiempo aumenta la relación entre el volumen producido (o vendido) y la magnitud del trabajo incorporado, significa que el producto promedio del trabajo ha mejorado; si disminuye, entonces la unidad de trabajo promedio es menos productiva.

- El personal no remunerado y el contratado por terceros, reducen el potencial crecimiento económico porque no incrementan el valor agregado. El primero, porque no percibe salario y prestación alguna; el segundo, porque representa la adquisición de un servicio externo que se registra como parte de los insumos intermedios.

- El ciclo ideal es ampliar la contratación de personal remunerado para aumentar 1) la masa de remuneraciones y los salarios y prestaciones medias, 2) el potencial valor agregado y margen de productividad, y 3) la capacidad de demanda en los mercados y el acceso a una canasta con mejores bienes y servicios (figura 1). El crecimiento económico y el bienestar de las familias están vinculados, por lo tanto, a la expansión del trabajo remunerado.

- Sin embargo, los estratos de ingreso están condicionados a la formación y actualización de las capacidades técnicas del capital intelectual, así como la capacidad de organización de los trabajadores como gremio para negociar con sus empleadores mejores condiciones de trabajo.

- El aumento del valor agregado mejora potencialmente la productividad. Su nivel está correlacionado con cuatro elementos: 1) Las capacidades empresariales; 2) La calidad del capital intelectual; 3) El avance científico-tecnológico y la innovación aplicada en los procesos de producción y en el diseño de bienes y servicios; y 4) El desarrollo de infraestructura de apoyo a la producción.

- La intervención del gobierno se refleja, al menos, en cuatro órdenes: 1) La protección a la vida y de los bienes materiales de las personas físicas y morales, 2) La observancia estricta de la ley, 3) La transparencia y rendición de cuentas de los recursos públicos destinados a la prestación de servicios y la edificación de infraestructura; y 4) La simplificación de la normatividad para el establecimiento de empresas. 
Figura 1

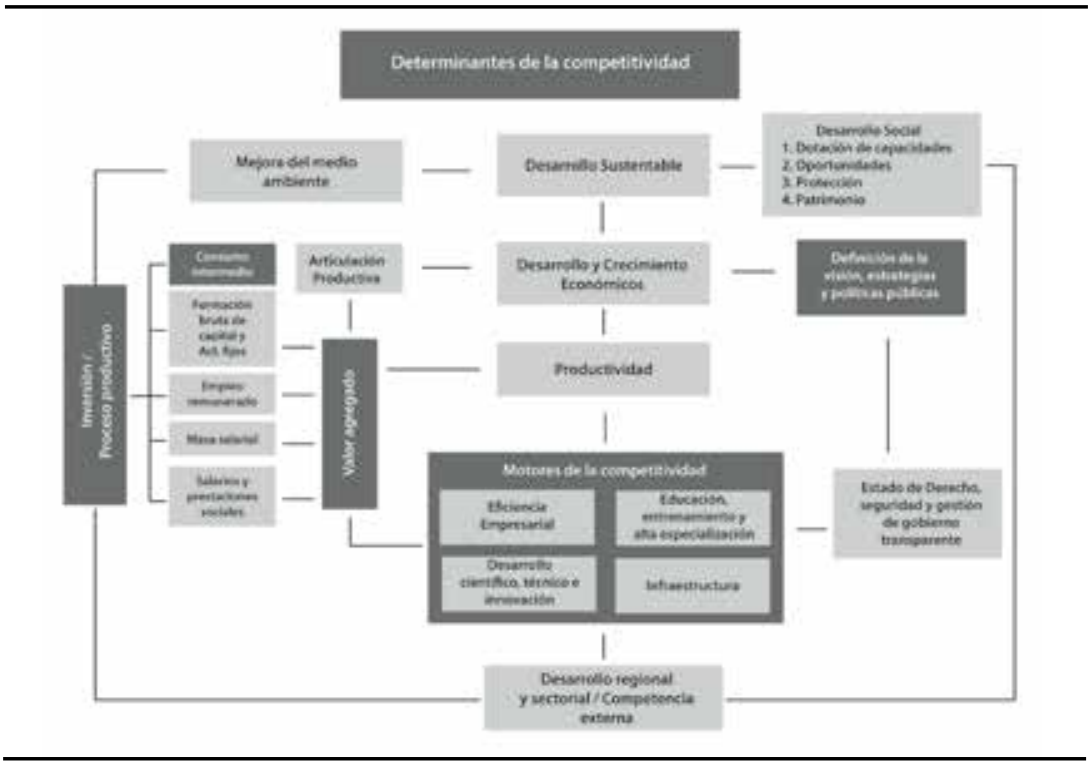

Fuente: Elaboración a partir de Altamirano y Camargo (2012).

- La expansión económica y la distribución de la riqueza son factores necesarios para reducir la pobreza y la desigualdad social, que se manifiesta en el acceso a la seguridad social y la dotación de capacidades; la expansión de oportunidades en los campos de la vida económica, social y cultural; y la formación de un patrimonio familiar, que incluye la vivienda, el ahorro, la infraestructura y servicios públicos de calidad.

- La productividad condiciona a largo plazo la calidad de vida de una nación, porque determina el nivel de ingreso per cápita, el salario medio y el rendimiento del capital. El nivel de eficiencia y rendimiento es fundamental para competir en los mercados en forma sostenida a largo plazo.

- La productividad requiere de un nivel adecuado de integración productiva, en la que la proporción del consumo intermedio tienda a ser menor a la del valor agregado en el producto final $(\mathrm{CI}+\mathrm{VA}=$ PBT). El cálculo de la productividad, por unidad de trabajo u horas laboradas, no debe adicionar el trabajo no remunerado ni el contra- 
tado por terceros, ya que no crean valor agregado; el hacerlo reduce su dimensión de manera indebida.

- Finalmente, el crecimiento económico y el bienestar social está en función de la expansión del trabajo remunerado; por lo tanto, para las políticas públicas debe ser un punto de atención.

Bajo este enfoque, la productividad y la competitividad están asociadas a la expansión económica del capital y la prosperidad social. Una economía abierta capaz de mejorar la producción de bienes prestación de servicios en términos de calidad y precio, es una economía productiva y competitiva. La condición es que el crecimiento del valor agregado debe ser mayor al del consumo de bienes intermedios. Ello supone (Camargo, 2013: 66-68):

1) La articulación de los mercados internos y su integración a los globales, con el propósito de reducir el desequilibrio externo a través de la proveeduría local y la atracción de inversión extranjera directa unida a su cadena de valor.

2) La reducción de la informalidad y el aumento del empleo directo, vinculados a mejores salarios y prestaciones, que al tiempo que elevan la participación en el valor agregado y la productividad, mejoran las condiciones de equidad en las familias.

3) La disposición de políticas sociales orientadas a la protección y la dotación de capacidades para insertar a la población en las actividades productivas; $\mathrm{y}$

4) Atender el principio de sustentabilidad: satisfacer las necesidades de crecimiento económico y calidad de vida respetando y protegiendo el medio ambiente, utilizando los recursos naturales de forma razonable en el presente para para salvaguardar el futuro de las próximas generaciones.

En el mundo actualmente domina la idea de que el aumento del salario real de los trabajadores reduce la producción, el empleo y la productividad. Se afirma que cualquier inducción a favor del empleo y del salario es insostenible a largo plazo porque se traduce en el incremento de la inflación; fenómeno que, al final, deteriora no sólo el ingreso sino también la demanda global. El impacto directo, se piensa en estos 
círculos, es el estancamiento económico, la caída de la productividad y la competitividad. Para resarcir el equilibrio es necesario moderar los salarios para fomentar, al mismo tiempo, el empleo total. Si los salarios se reducen, los costos de las empresas disminuyen, por lo que la demanda comienza a crecer; particularmente la que está relacionada con el comercio internacional (Palley, 2011: 250, 264-265)4. Desde esta perspectiva, la competitividad está vinculada a la cuantía del salario. Si la productividad es el medio con el que se compite en los mercados, su margen debe estar por encima de los salarios reales a fin de inyectar rentabilidad a la inversión. Si se cumple esta condición, la desocupación tenderá a descender, principalmente en aquellos segmentos con menor calificación. En términos sociales, esta situación representa una oportunidad para ampliar el desarrollo social a partir del empleo, ya que existe una correlación inevitable entre el crecimiento y la equidad: "el precio que se debe pagar por un mayor índice de empleo es un sector con bajos salarios" (Storm, 2011: 223).

Sin embargo, a lo largo de tres décadas, en las naciones que conforman la Organización para la Cooperación y el Desarrollo Económicos (OCDE), los salarios reales se han ido estancando. Tres relaciones económicas ilustran lo que sucede: 1) Cuando crecía la productividad, los salarios crecían en paralelo; ahora, en EEUU y en otros lados, los salarios son estables. 2) Cuando aumentaban las ganancias, los salarios aumentaban; ahora, los salarios no cambian. 3) Cuando aumentaba el empleo, los salarios promedio también aumentaban; ahora, los salarios promedio incluso pueden caer, porque los trabajos nuevos pagan menos (Standing, 2017). Ante el riesgo económico y político que implica una mayor precariedad del ingreso de los trabajadores, es necesario constituir un nuevo sistema de distribución del ingreso, que supone un nuevo entramado social en el que las élites realicen verdaderas concesiones o encontrar los valores que reclaman conservación, tolerancia, libertad, seguridad económica y diversidad cultural (Standing, 2017).

4 También se recomienda Hoffer (2011), Jackson (2011), Janssen (2011), Storm (2011), Van Treeck (2011) y Weiguang (2011), quienes analizan los efectos de la crisis financiera de 2009 y las repercusiones en las políticas y acciones para reiniciar un nuevo ciclo de expansión con base en la profundización las reformas económicas, que van desde la privatización de los servicios públicos y la mayor apertura comercial y financiera, hasta la reducción de los salarios, la desregulación de los mercados de trabajo y el aumento de la edad de jubilación, junto con pensiones e impuestos sobre el trabajo más bajos. 
Desde finales de los ochenta, la política laboral en México ha sido tutelada por estos principios. El impacto a largo plazo ha sido la contención al crecimiento de la producción y el descenso de la productividad laboral, además de la extensión de la pobreza y desigualdad por todo el territorio nacional. A ello contribuyen las altas tasas de desocupación e informalidad, la tendencia a la baja del empleo permanente, el amplio uso de los esquemas de subcontratación y el lento crecimiento de los salarios reales. Al cuarto trimestre de 2018, la población económicamente activa (PEA) era de 56 millones de personas, de las cuales $3.3 \%$ eran desocupadas. Esta tasa, que es corta en los estándares de la OCDE, aún no se aproxima a la de 2005, cuando se ubicó en 3.1\%, la tasa más baja en la historia reciente del país (cuadro 3). Su radio afecta a 1 millón 829 mil personas, las cuales se ven limitadas para satisfacer sus necesidades básicas por la ausencia de ingreso.

Del lado de la informalidad laboral, desde hace más de una década se ha mantenido en estrecho rango. En promedio, la tasa se ubica en $58.5 \%$ anual y la del sector informal (que está vinculada a las actividades empresariales con recursos de los hogares), en 27.6 por ciento. A partir de 2014, cuando se pone en marcha el régimen de incorporación fiscal $^{5}$, la informalidad total paulatinamente se redujo porque el registro de cotizantes en el IMSS incluyó las nuevas plazas y a las personas que ya trabajaban pero no estaban incorporadas en la seguridad social (Piz, 2018). En 2018, la tasa de informalidad alcanzó su punto más bajo con $56.6 \%$, lo cual incluye a 30.7 millones de personas, de las cuales 14.9 millones (27.4 puntos) pertenecen al sector informal. Entre uno y otro año, la expansión de la informalidad laboral fue de 1 millón 836 mil personas, de las cuales $64.2 \%$ correspondieron al sector informal.

\footnotetext{
Este régimen tiene una fase transitoria que condiciona sus beneficios graduales al cumplimiento permanente de las obligaciones tributarias, de tal forma que en el primer año (2014) las empresas y personas físicas incorporadas obtengan la exención total del pago del impuesto sobre la renta, $90 \%$ de exención en el segundo año, y así sucesivamente hasta pagar $100 \%$ del impuesto en el décimo primer año. En 2015, la SHCP consideró dar una prórroga por un año, por lo que entró en vigencia en 2016. A cambio, las empresas y los trabajadores incorporados tienen el pleno acceso a las prestaciones del IMSS y al sistema de financiamiento que administra el INFONAVIT. Para ello el gobierno federal otorga un subsidio para el pago de las cuotas obrero-patronales a las personas físicas que tributen en el referido régimen de incorporación fiscal. Véase sus particularidades en el "Decreto por el que se otorgan estímulos para promover la incorporación a la seguridad social". Diario Oficial de la Federación, 08 de abril de 2014, p.1.
} 


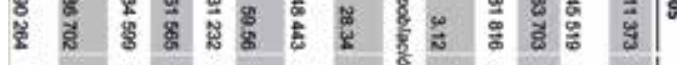

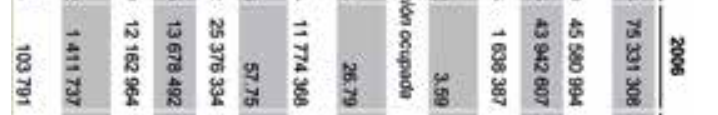

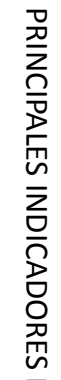

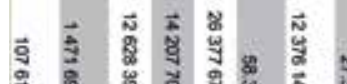

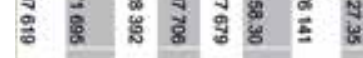

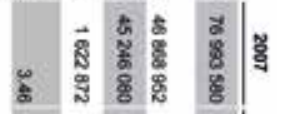

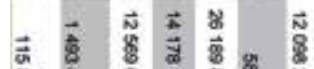

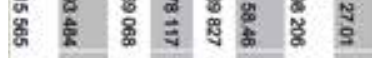

$\vec{\omega}$

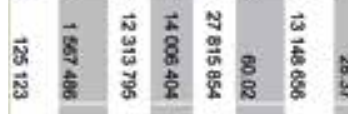

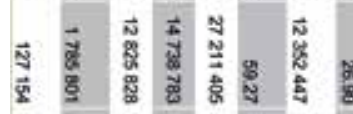

\&.

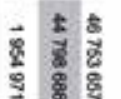

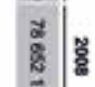

\% 8

स \&

\&.

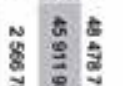

\&

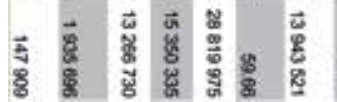

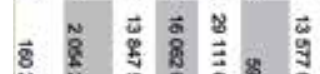

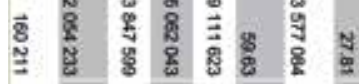

㟧

N $\begin{array}{ll}8 \\ \text { के }\end{array}$

密

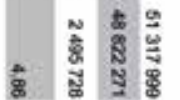

$\overrightarrow{8} \quad \vec{g}$ 尊

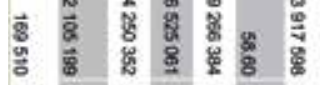

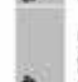

के

事

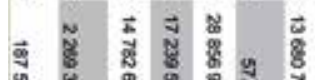

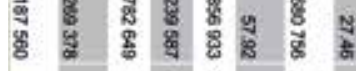

\&.

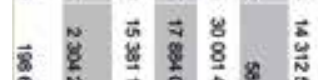

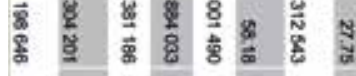

( ) :

空

葸

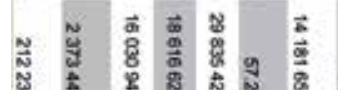

के

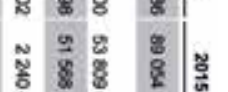

莡

要

है

mo

岁 $\equiv$ \%

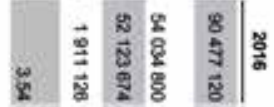

ฐ

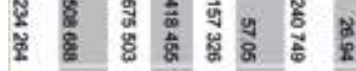

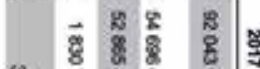
\&

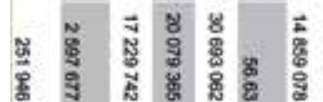

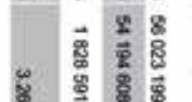

量

:

量 
Ante la reducción de la tasa de informalidad, el mercado formal se amplió, aunque la cantidad y la calidad del empleo no es la deseada. Entre 2010 y 2018, el número de plazas aumentó en 5 millones 340 mil trabajadores, lo que equivale a 593 mil por año, valor que representa la mitad de lo que requiere la economía para satisfacer la demanda de los jóvenes que se incorporan al mercado laboral y la demanda acumulada no satisfecha de las personas que han perdido su empleo. El trabajo permanente sigue prevaleciendo en el total, pero tiende a perder participación. En este lapso se ha contraído en más de un punto porcentual, al pasar de $87.0 \%$ a 85.8 . En 2005, la participación era de 89.5 por ciento. El empleo eventual urbano ha ocupado este espacio.

Por otra parte, la subcontratación u outsourcing ha cobrado importancia. En principio, el esquema se utiliza de forma complementaria al objeto productivo de las empresas para hacerlas más eficientes, pero no necesariamente es así, ya que el personal reclutado tiende a operar directamente en los procesos. El problema es que llega a funcionar de manera fraudulenta. Según la consultora ManpowerGroup, 80.0\% de los trabajadores temporales inscritos en el IMSS aparentemente tiene un patrón distinto para el que laboran, sin embargo, éste forma parte de la empresa subcontratante (Migueles, 2018). El avance ha sido acelerado. En 2003, representaba $6.2 \%$ del total del personal ocupado; diez años después es de 14.0 por ciento. De los diferentes tipos en que se clasifica el personal ocupado, fue el de mayor incremento, al pasar de 1 millón de trabajadores a 3 millones, lo que representa 200.0\% más. En cambio, el trabajo independiente aumentó $44.8 \%$ y el empleo no remunerado, 35.0 por ciento. El más rezagado fue el empleo remunerado, que creció en 15.6 por ciento (cuadro 4 ).

El impacto del outsourcing se extiende a otros rubros. Mientras la masa salarial de los trabajadores subordinados aumentó $10.1 \%$ en términos reales y las remuneraciones medias retrocedieron $4.8 \%$, los pagos a otra razón social por el suministro de personal aumentaron 163.7 por ciento. De igual forma, estos pagos incrementaron su participación como proporción del gasto total de 1.5 a $3.0 \%$, en el gasto por consumo de bienes y servicios de 1.9 a $3.4 \%$, y en el consumo intermedio de 3.4 a 5.1 por ciento. En contraste, las remuneraciones totales redujeron su participación en el valor agregado en 1.6 puntos, de 24.9 a 23.3 por ciento. La repercusión inmediata es que la productividad laboral del trabajador remunerado avanzó solo $1.6 \%$ a lo largo de una 
década. En términos prácticos, el ascenso del outsourcing ha contribuido a mejorar la competitividad empresarial mediante la dilución de obligaciones contractuales y costos salariales, pero ha deteriorado la capacidad de compra de los trabajadores con la caída acumulada de los salarios reales. Al mismo tiempo ha extendido la informalidad laboral ya que la mayoría de este tipo de trabajadores no tiene acceso a la seguridad social y a otras prestaciones, tales como el sistema de ahorro para el retiro o el INFONAVIT. La suma de estos elementos daña el crecimiento del valor agregado, la productividad laboral del país y al erario ${ }^{6}$.

\section{Cuadro 4}

MÉXICO: PRINCIPALES INDICADORES DE LOS CENSOS ECONÓMICOS, 2004 - 2014 (VALORES CONSTANTES)

\begin{tabular}{|c|c|c|c|}
\hline Concepto & 2003 & 2008 & 2013 \\
\hline 1 Personal ocupado total & 16239536 & 20116834 & 21576358 \\
\hline a) Personal dependiente de la razón social & 14849873 & 17408728 & 17998111 \\
\hline - Personal remunerado total & 10551797 & 11413884 & 12197140 \\
\hline - Propietarios, familiares y otros trabajadores no remunerados & 4298076 & 5994844 & 5800971 \\
\hline b) Personal no dependiente de la razón social & 1389663 & 2708106 & 3578247 \\
\hline - Personal suministrado por otra razón social & 1002697 & 2342303 & 3018127 \\
\hline - Personal por honorarios o comisiones sin sueldo base & 386966 & 365803 & 560120 \\
\hline 2 Total de remuneraciones (millones de pesos) & 1159887 & 1267695 & 1276870 \\
\hline Remuneraciones medias por trabajador remunerado (pesos) & 109923 & 111066 & 104686 \\
\hline $\begin{array}{l}3 \text { Pagos a otra razón social que contrató y proporcionó personal } \\
\text { (millones de pesos) }\end{array}$ & 142444 & 321948 & 375651 \\
\hline 4 Gasto por bienes y servicios & 7617493 & 11976690 & 11196943 \\
\hline 5 Total de gastos (millones de pesos) & 9464963 & 14435749 & 12504166 \\
\hline 6 Producción bruta total (millones de pesos) & 8870253 & 12611447 & 12806138 \\
\hline • Consumo intermedio (m\}illones de pesos) & 4203266 & 6636233 & 7325752 \\
\hline - Valor agregado censal bruto (millones de pesos) & 4666988 & 5975213 & 5480386 \\
\hline - Productividad laboral (pesos) & 442293 & 523504 & 449317 \\
\hline
\end{tabular}

Fuente: INEGI. (2004, 2009, 2014 y 2015b).

6 Según la consultora Staffing Industry Analysts, en México existen 900 empresas de outsourcing, pero únicamente 40 declaran impuestos ante Hacienda y 100 otorgan seguridad social a sus trabajadores. Datos adicionales de la firma Adecco Thierry Gonnet aseguran que las empresas formales, agrupadas en la Asociación Mexicana de Capital Humano, emplean a 147 mil 473 trabajadores, cantidad mínima si se compara con los 4 millones 920 mil personas que se estima laboran bajo este régimen, pero que representa un mercado de 1 mil 500 millones de dólares anuales (Gascón, 2015: 3). Por otra parte, el SAT ha identificado 6 mil empresas con 7.6 millones de trabajadores que 
En términos sociales, el deterioro laboral ha prolongado el abatimiento de la pobreza. En 2008 abarcaba a 49 millones 489 mil personas, lo cual representaba $44.4 \%$ de la población del país. Una década después la cifra aumentó a 52 millones 426 mil que equivale a 5.9\% más, aunque como porcentaje de la población total se redujo en 2 puntos y medio al ubicarse en 41.9 por ciento. Si se agrega para 2018 la población vulnerable por carencias sociales $(29.3 \%)$ y vulnerable por ingreso (6.9\%), el conjunto representa $78.1 \%$ de la población nacional, es decir, 97 millones 730 mil personas que viven en condiciones de pobreza y desigualdad. El restante 21.9\% (27 millones 352 mil personas) no son pobres ni vulnerables (CONEVAL, 2019).

En este escenario, es válido preguntar si existe margen para incrementar el empleo, los salarios y las prestaciones del empleo remunerado, considerando que un aumento podría repercutir negativamente en la estabilidad de precios, que desde 2005 oscila en 4.16 por ciento anual. Como se ha mencionado (Camargo, 2013: 21-23), el incremento de la productividad estimula el movimiento de los salarios, que al aumentar favorece la demanda y el pleno empleo. Si la demanda crece, la inversión también aumenta, reiniciando el ciclo de mayor productividad (véase Palley, 2011).

Los supuestos del modelo de crecimiento del circulo virtuoso son: a) Las empresas están limitadas por el deterioro de la demanda en los mercados de bienes, y b) Un aumento en la participación salarial de los ingresos globales que van a los hogares de los trabajadores, incrementa la demanda agregada porque la tendencia al consumo es mayor (Palley, 2011: 250). La consideración básica del modelo es que, a un aumento en los salarios, los márgenes de empleo suben al distender la limitación de la demanda, por lo que el efecto en la caída de las ganancias, por el incremento del salario real, queda compensado por la mayor activa-

evaden impuestos a través del outsourcing, el abuso de pagos exentos y la subdeclaración. Durante 2017 eludieron alrededor de 21 mil 467 millones de pesos, cantidad que equivale a 3.39\% del impuesto sobre la renta (ISR) recaudado en este año (Flores, 2019). Ante la situación, la autoridad hacendaria ha introducido esquemas de regulación a través de modificaciones a las leyes del ISR y al valor agregado (IVA) a partir de 2017, cambios que obligan a las empresas que utilizan los servicios de terceros entregar copias de la nómina con acuse de recibo de los trabajadores, la comprobación del entero del ISR, el comprobante de la declaración del IVA y, recientemente en 2018, el comprobante de pago de las cuotas del IMSS y que sea depositada en el buzón tributario de la empresa contratante. El propósito es evitar la elusión fiscal y lavado de dinero (Barranco, 2017; Flores, 2018; El Financiero, 2018). 
ción de la capacidad y la productividad laboral. En la misma dirección, el incremento de la demanda no solamente aumenta la productividad laboral, sino también el progreso tecnológico:

Si la economía está basada en los salarios, la demanda y la utilización de la capacidad aumentan cuando los salarios (reales) son más elevados. Esto incrementa la rentabilidad y, a su vez, motiva mayores inversiones por parte de las empresas. Asimismo, la acumulación de capital aumenta en respuesta al crecimiento de la demanda agregada (el efecto acelerador keynesiano). El resultado es una secuencia de ciclos de crecimiento de la demanda y un aumento en la utilización y, por lo tanto, en el índice de ganancias. En primer lugar, los equipos recientemente instalados cuentan con la última tecnología de producción y, en consecuencia, son más productivos que las inversiones anteriores en capital social. En segundo lugar, el aumento de la demanda, provocado por los salarios más elevados amplía la brecha en la división del trabajo de toda la economía y conduce a un aprendizaje más rápido a través de la práctica (en las empresas), que son procesos que finalmente se reflejan en un mayor crecimiento de la productividad laboral. En ambas explicaciones, el mayor crecimiento de la demanda se asocia con el mayor crecimiento de la productividad laboral; este vínculo positivo se conoce [...] como la relación Kaldor-Verdoorn (Palley, 2011: 225-226).

El modelo define que el crecimiento sostenido y elevado de los salarios reales deriva en mayor productividad, pues alienta la intensificación del capital y la proporción de trabajadores altamente calificados, ya que fomenta el progreso tecnológico para ahorrar en mano de obra. El resultado a largo plazo es el incremento de las tasas de acumulación de capital social y la formulación de un régimen de desarrollo estable. Lo importante del modelo es que muestra la posibilidad de un capitalismo cooperativo basado en salarios (Palley, 2011). Sobre esta base teórica se evalúa la posibilidad de incrementar el ingreso salarial de los trabajadores remunerados en México a partir de las variables de productividad y el costo de la mano de obra (CUMO) (para el método de cálculo de sus componentes: INEGI, 2016a). 


\section{PRODUCTIVIDAD Y COSTO DE LA MANO DE OBRA REMUNERADA}

La contención salarial ha sido uno de los principales mecanismos para impulsar la competitividad de las empresas en México; el costo-país ha sido pausar el crecimiento económico y el margen de productividad. De acuerdo con la PTF, la contribución de los servicios laborales ha tendido a ser menos participativa particularmente después de la crisis financiera de 2009, que incluso está por debajo de la aportación de los servicios utilizados para la producción; aun así, su favorable desempeño genera expectativas sobre la factibilidad de modificar la política salarial sin atentar la estabilidad de precios, ya que las remuneraciones medias por unidad de trabajo o por hora trabajada, y el CUMO han evolucionado más lentamente que la productividad laboral.

\subsection{Productividad por unidad de trabajo remunerado}

Entre 2001 y 2017, la remuneración media por puesto de trabajo se ha incrementado en términos reales $1.02 \%$ anual, lo cual ha favorecido la expansión de la productividad laboral en 0.71 por ciento. Esta tasa es más del doble de lo que costó la mano de obra, la cual alcanzó $0.33 \%$ en este periodo. De igual forma, si se compara el aumento del producto con el del empleo remunerado $(2.01 \%$ contra $1.28 \%)$, la productividad también se vio beneficiada (cuadro 5).

La productividad modifica su comportamiento tras la crisis financiera. Entre 2001 y 2010, el CUMO era alto en relación con lo que rendía productivamente: $0.80 \%$ contra $0.44 \%$ anual, lo cual es resultado de la recuperación del salario medio, que varió a un ritmo de $1.23 \%$ cuando en la década de los noventa se movió en alrededor de $1.0 \%$, situación que apuntaló el margen de productividad en 1.36\% y un CUMO de - 0.39 por ciento. Con la crisis, se retorna a una política de estabilización y control salarial, por lo que la remuneración media acompasó su ritmo por abajo del promedio de largo plazo; de 2011 a 2017 el incremento es de $0.73 \%$ anual, lo que aumenta la rentabilidad a $1.09 \%$ y contrae el CUMo a $-0.35 \%$, tendencia que se acentúa desde 2012. Al mismo 
tiempo, el empleo remunerado se reactiva de manera inestable y varía en $1.66 \%$ anual; desde 2014 se estabiliza su ritmo, lo cual coincide con la operación del régimen de incorporación fiscal, que tiene como objetivo formalizar el mercado laboral; este ritmo es inferior al que se observa en el PIB, que durante el periodo aumenta en 2.76 por ciento.

Cuadro 5

MÉXICO: PRODUCTIVIDAD Y COSTO UNITARIO DE LA MANO DE OBRA (CUMO) POR UNIDAD DE TRABAJO REMUNERADO, 2001-2017 (VARIACIÓN ANUAL, $2013=100)$

\begin{tabular}{|c|c|c|c|c|c|c|}
\hline Año & $\begin{array}{c}\text { Valor Agregado } \\
\text { Bruto }^{1 /}\end{array}$ & $\begin{array}{c}\text { Puestos de } \\
\text { Trabajo } \\
\text { Remunerados }\end{array}$ & Masa Salarial & $\begin{array}{c}\text { Productividad } \\
\text { Laboral por } \\
\text { Puesto }\end{array}$ & $\begin{array}{c}\text { Remuneración } \\
\text { Media }\end{array}$ & $\begin{array}{c}\text { CUMO por } \\
\text { Puesto de } \\
\text { Trabajo }\end{array}$ \\
\hline 2001 & -0.45 & -0.88 & 3.04 & 0.43 & 3.96 & 3.51 \\
\hline 2002 & -0.07 & -1.69 & 1.88 & 1.65 & 3.62 & 1.94 \\
\hline 2003 & 1.45 & 2.74 & 1.55 & -1.26 & -1.16 & 0.10 \\
\hline 2004 & 3.91 & 2.95 & 2.80 & 0.93 & -0.15 & -1.08 \\
\hline 2005 & 2.28 & 1.65 & 3.09 & 0.62 & 1.42 & 0.80 \\
\hline 2006 & 4.37 & 3.33 & 5.13 & 1.01 & 1.74 & 0.72 \\
\hline 2007 & 2.32 & 2.01 & 3.05 & 0.30 & 1.02 & 0.72 \\
\hline 2008 & 1.04 & 1.51 & 2.84 & -0.46 & 1.31 & 1.78 \\
\hline 2009 & -5.24 & -2.90 & -2.60 & -2.40 & 0.31 & 2.78 \\
\hline 2010 & 5.16 & 1.52 & 1.74 & 3.58 & 0.21 & -3.25 \\
\hline 2011 & 3.65 & 2.48 & 4.01 & 1.14 & 1.49 & 0.35 \\
\hline 2012 & 3.73 & 2.76 & 3.66 & 0.95 & 0.88 & -0.07 \\
\hline 2013 & 1.37 & 0.78 & 1.31 & 0.58 & 0.52 & -0.06 \\
\hline 2014 & 2.67 & 1.08 & 1.32 & 1.57 & 0.23 & -1.32 \\
\hline 2015 & 3.18 & 1.79 & 3.07 & 1.37 & 1.26 & -0.11 \\
\hline $2016^{/ R}$ & 2.73 & 1.82 & 2.71 & 0.89 & 0.87 & -0.02 \\
\hline $2017^{/ P}$ & 1.99 & 0.88 & 0.73 & 1.10 & -0.15 & -1.24 \\
\hline
\end{tabular}

Fuente: Con base en INEGI (2018).

La conclusión es que tanto del lado salario medio como del empleo remunerado existen márgenes para incrementarlos sin afectar la estabilidad de precios.

\subsection{Productividad por hora trabajada}

El comportamiento del costo por hora trabajada es similar al de por unidad de trabajo, solo que el nivel de productividad disminuye marginalmente en cada etapa del análisis. De 2001 a 2017, la productividad por puesto de trabajo ha variado en $0.71 \%$ anual, en tanto que por hora trabajada es de $0.64 \%$; de 2001 a 2010 son iguales en $0.44 \%$ anual, mientras que de 2011 a 2017 son de 1.09 y $0.93 \%$, lo que indica que es más rentable para la economía contratar trabajadores por jornada completa que por fracción (cuadro 6). También revela que el salario 
medio por trabajador ha tenido mayor movilidad que el que se paga por hora trabajada. En el largo plazo, las variaciones son de $1.02 \%$ anual contra $0.92 \%$; en la primera década del nuevo siglo son semejantes en $1.23 \%$, y en lo que va de la segunda son de $0.73 \%$ contra $0.58 \%$ anual. Los saldos, por lo tanto, son distintos en rentabilidad: La productividad de una unidad de trabajo ha sido 2.16 veces mayor que su costo unitario cuando por hora trabajada es de 1.97 (2001-2017). Para la primera década, en ambos conceptos, el cumo creció al doble que el margen de productividad: $0.80 \%$ contra $0.44 \%$, mientras que, en la segunda, la rentabilidad se recupera en mayor proporción en una unidad de trabajo que por hora laborada: 3 veces contra 2.6.

\section{Cuadro 6}

MÉXICO: PRODUCTIVIDAD Y COSTO UNITARIO DE LA MANO DE OBRA POR HORA TRABAJADA DEL PERSONAL REMUNERADO, 2001-2017 (VARIACIÓN ANUAL, $2013=100)$

\begin{tabular}{|c|c|c|c|c|c|c|}
\hline Año & $\begin{array}{c}\text { Valor Agregado } \\
\text { Bruto }^{1 /}\end{array}$ & $\begin{array}{c}\text { Horas } \\
\text { Trabajadas }\end{array}$ & Masa Salarial & $\begin{array}{c}\text { Productividad } \\
\text { por Hora } \\
\text { Trabajada }\end{array}$ & $\begin{array}{c}\text { Remuneración } \\
\text { Media }\end{array}$ & $\begin{array}{c}\text { CUMO por Hora } \\
\text { Trabajada }\end{array}$ \\
\hline 2001 & -0.45 & -1.12 & 3.04 & 0.68 & 4.21 & 3.51 \\
\hline 2002 & -0.07 & -1.70 & 1.88 & 1.66 & 3.64 & 1.94 \\
\hline 2003 & 1.45 & 2.11 & 1.55 & -0.65 & -0.55 & 0.10 \\
\hline 2004 & 3.91 & 3.23 & 2.80 & 0.67 & -0.42 & -1.08 \\
\hline 2005 & 2.28 & 1.18 & 3.09 & 1.09 & 1.89 & 0.80 \\
\hline 2006 & 4.37 & 3.27 & 5.13 & 1.07 & 1.80 & 0.72 \\
\hline 2007 & 2.32 & 2.21 & 3.05 & 0.10 & 0.82 & 0.72 \\
\hline 2008 & 1.04 & 1.55 & 2.84 & -0.50 & 1.27 & 1.78 \\
\hline 2009 & -5.24 & -2.12 & -2.60 & -3.19 & -0.50 & 2.78 \\
\hline 2010 & 5.16 & 1.62 & 1.74 & 3.48 & 0.11 & -3.25 \\
\hline 2011 & 3.65 & 2.47 & 4.01 & 1.15 & 1.50 & 0.35 \\
\hline 2012 & 3.73 & 3.34 & 3.66 & 0.38 & 0.32 & -0.07 \\
\hline 2013 & 1.37 & 0.79 & 1.31 & 0.57 & 0.51 & -0.06 \\
\hline 2014 & 2.67 & 1.37 & 1.32 & 1.28 & -0.05 & -1.32 \\
\hline 2015 & 3.18 & 1.84 & 3.07 & 1.31 & 1.20 & -0.11 \\
\hline $2016^{/ R}$ & 2.73 & 1.79 & 2.71 & 0.93 & 0.91 & -0.02 \\
\hline $2017^{P P}$ & 1.99 & 1.09 & 0.73 & 0.90 & -0.36 & -1.24 \\
\hline
\end{tabular}

Fuente: Con base en INEGI (2018). SCNM: Productividad Total de los Factores Modelo KLEMS.

Al final, la evaluación de ambos métodos indica lo siguiente. 1) Es menos rentable contratar por hora de trabajo que por unidad de trabajo, porque el nivel de productividad es menor en relación al costo. 2) En ambos, existe margen de maniobra para mover al alza la escala salarial debido a un costo unitario moderado, lo que evita presiones inflacionarias y la caída de la productividad, y; 3) Es factible, en cada caso, incrementar el número de horas laborables o el número de plazas porque la productividad es superior a los costos unitarios, los cuales han tendido 
a la baja tras la crisis financiera; también lo es porque el número de horas laborables o el número de puestos de trabajo se han expandido a menor ritmo que el producto (cuadro 7). En este escenario, es factible modificar la política salarial y de empleo vigente.

\section{Cuadro 7}

PRODUCTIVIDAD Y COSTO UNITARIO DE MANO DE OBRA REMUNERADA EN MÉXICO POR PUESTO DE TRABAJO U HORA LABORADA. VARIACIÓN ANUAL POR PERIODOS, 1991-2017 $(2013=100)$

\begin{tabular}{|c|c|c|c|c|c|c|c|}
\hline Periodo / Concepto & VAB & $\begin{array}{c}\text { Puestos de } \\
\text { Trabajo } \\
\text { Remunerado } \\
\end{array}$ & $\begin{array}{c}\text { Horas } \\
\text { Trabajadas }\end{array}$ & $\begin{array}{c}\text { Masa } \\
\text { Salarial }\end{array}$ & $\begin{array}{c}\text { Productividad } \\
\text { Laboral }\end{array}$ & $\begin{array}{c}\text { Remuneración } \\
\text { Media }\end{array}$ & CUMO \\
\hline \multicolumn{8}{|c|}{ Por Puesto de Trabajo } \\
\hline $1991-2000$ & 3.86 & 2.44 & - & 3.54 & 1.36 & 1.01 & -0.39 \\
\hline $2001-2010$ & 1.48 & 1.02 & - & 2.25 & 0.44 & 1.23 & 0.80 \\
\hline $2010-2017$ & 2.76 & 1.66 & - & 2.40 & 1.09 & 0.73 & -0.35 \\
\hline $2001-2017$ & 2.01 & 1.28 & - & 2.31 & 0.71 & 1.02 & 0.33 \\
\hline \multicolumn{8}{|c|}{ Por Hora Trabajada } \\
\hline $1991-2000$ & 3.86 & - & 2.36 & 3.54 & 1.46 & 1.10 & -0.39 \\
\hline $2001-2010$ & 1.48 & - & 1.02 & 2.25 & 0.44 & 1.23 & 0.80 \\
\hline $2010-2017$ & 2.76 & - & 1.81 & 2.40 & 0.93 & 0.58 & -0.35 \\
\hline $2001-2017$ & 2.01 & - & 1.35 & 2.31 & 0.64 & 0.96 & 0.33 \\
\hline
\end{tabular}

Fuente: Con base en INEGI (2018).

\section{LA OCUPACIÓN Y EMPLEO EN LAS REGIONES DE MÉXICO?}

El deterioro económico del país y sus regiones se puede atribuir al comportamiento del mercado laboral. La Encuesta nacional de ocupación y empleo (ENOE) vislumbra la capacidad potencial que tienen el centro y occidente de México en la demanda nacional considerando la

Las regiones se definen a partir de la clasificación que hace la Cámara de Diputados federal para la asignación del presupuesto: 1) Centro: Ciudad de México, Hidalgo, México, Morelos, Puebla y Tlaxcala; 2) Sur Sureste: Campeche, Chiapas, Guerrero, Oaxaca, Quintana Roo, Tabasco, Veracruz y Yucatán; 3) Occidente: Aguascalientes, Colima, Guanajuato, Jalisco, Michoacán, Nayarit, Querétaro, San Luis Potosí y Zacatecas; 4) Noroeste: Baja California, Baja California Sur, Sinaloa y Sonora; 5) Noreste: Chihuahua, Coahuila, Durango, Nuevo León y Tamaulipas (Centro de Estudios de las Finanzas Públicas, 2007: 1). Sobre la pertinencia de esta clasificación regional: Centro de Estudios Sociales y de Opinión Pública (2016: 27-31). 
dimensión de su población económicamente activa (PEA) y población ocupada. En la primera zona se ubica $32.1 \%$ de la PEA y $31.9 \%$ de la ocupada; en la segunda, 22.9 y $23.0 \%$, respectivamente (cuadro 8 ). Sin embargo, el potencial del centro declina cuando se observa que la participación en la población desocupada del país es de $36.8 \%$; de $39.8 \%$ en el sector informal, y de más de un tercio en la informalidad laboral. Si se agregan las respectivas tasas, la comparación indica que son mayores a la media nacional: medio punto en la de desocupación, 6.4 puntos en la del sector informal y 3.5 en la de informalidad laboral.

\section{Cuadro 8}

SELECCIÓN DE INDICADORES DE OCUPACIÓN Y EMPLEO EN LAS REGIONES DE MÉXICO, 2018)

\begin{tabular}{|c|c|c|c|c|c|c|c|c|}
\hline ENTIDAD & PEA & $\begin{array}{c}\text { Personal } \\
\text { Ocupado } \\
\text { (PO) }\end{array}$ & $\begin{array}{c}\text { Personal } \\
\text { Desocupado }\end{array}$ & $\%$ de PEA & $\begin{array}{c}\text { Ocupación } \\
\text { en el Sector } \\
\text { Informal }\end{array}$ & $\%$ de la PO & $\begin{array}{c}\text { Informalidad } \\
\text { Laboral }\end{array}$ & $\begin{array}{c}\text { Tasa de } \\
\text { Informalidad } \\
\text { Laboral }\end{array}$ \\
\hline NACIONAL & 56023199 & 54194608 & 1828591 & 3.26 & 14859078 & 27.42 & 30693062 & 56.63 \\
\hline \multicolumn{9}{|c|}{ Región 1 Centro Pais } \\
\hline 1 Ciudad de México & 4440317 & 4212542 & 227775 & 5.13 & 1236065 & 29.34 & 2055771 & 48.80 \\
\hline 2 Hidalgo & 1302465 & 1275340 & 27125 & 2.08 & 476146 & 37.33 & 971321 & 76.16 \\
\hline 3 México & 7924199 & 7619554 & 304645 & 3.84 & 2611564 & 34.27 & 4344365 & 57.02 \\
\hline 4 Morelos & 838342 & 820724 & 17618 & 2.10 & 279773 & 34.09 & 562771 & 68.57 \\
\hline 5 Puebla & 2849781 & 2777999 & 71782 & 2.52 & 1001949 & 36.07 & 2039396 & 73.41 \\
\hline 6 Tlaxcala & 603336 & 579067 & 24269 & 4.02 & 234954 & 40.57 & 420093 & 72.55 \\
\hline Total regional & 17958440 & 17285226 & 673214 & 3.75 & 5840451 & 33.79 & 10393716 & 60.13 \\
\hline \multicolumn{9}{|l|}{ Región 2 Sur Sureste } \\
\hline 1 Campeche & 433649 & 418568 & 15083 & 3.48 & 97442 & 23.28 & 258092 & 61.66 \\
\hline 2 Chiapas & 1969051 & 1899923 & 69128 & 3.51 & 405548 & 21.35 & 1478150 & 77.80 \\
\hline 3 Guerrero & 1559635 & 1540739 & 18896 & 1.21 & 513330 & 33.32 & 1212904 & 78.72 \\
\hline 4 Oaxaca & 1766964 & 1731946 & 35018 & 1.98 & 660277 & 38.12 & 1407073 & 81.24 \\
\hline 5 Quintana Roo & 872731 & 846060 & 26671 & 3.06 & 184606 & 21.82 & 406090 & 48.00 \\
\hline Tabasco & 1019337 & 939285 & 80052 & 7.85 & 306902 & 32.67 & 619711 & 65.98 \\
\hline 7 Veracnuz & 3330020 & 3238909 & 91111 & 2.74 & 901498 & 27.83 & 2196421 & 67.81 \\
\hline 8 Yucatán & 1100165 & 1084113 & 16052 & 1.46 & 357761 & 33.00 & 672490 & 62.03 \\
\hline Total regional & 12051552 & 11699541 & 352011 & 2.92 & 3427364 & 29.29 & 8250931 & 70.52 \\
\hline \multicolumn{9}{|c|}{ Región 3 Centro Occidente } \\
\hline 1 Aguascalientes & 584160 & 565560 & 18600 & 3.18 & 121320 & 21.45 & 239465 & 42.34 \\
\hline 2 Colima & 396857 & 382222 & 14635 & 3.69 & 69009 & 18.05 & 192980 & 50.49 \\
\hline 3 Guanajuato & 2659163 & 2557936 & 101227 & 3.81 & 667729 & 26.10 & 1363625 & 53.31 \\
\hline 4 Jalisco & 3797311 & 3700487 & 96824 & 2.55 & 812298 & 21.95 & 1826042 & 49.35 \\
\hline 5 Michoacán & 2014164 & 1964674 & 49490 & 2.46 & 604566 & 30.77 & 1356833 & 69.06 \\
\hline 6 Nayarit & 620909 & 598738 & 22171 & 3.57 & 145874 & 24.36 & 374319 & 62.52 \\
\hline 7 Querétaro & 861125 & 829255 & 31870 & 3.70 & 162536 & 19.60 & 351676 & 42.41 \\
\hline 8 San Luis Potosi & 1221282 & 1195177 & 26105 & 2.14 & 273756 & 22.91 & 667531 & 55.85 \\
\hline 9 Zacatecas & 661187 & 644993 & 16194 & 2.45 & 145929 & 22.62 & 401115 & 62.19 \\
\hline Total regional & 12816158 & 12439042 & 377116 & 2.94 & 3003016 & 24.14 & 6773587 & 54.45 \\
\hline \multicolumn{9}{|l|}{ Región 4 Noroeste } \\
\hline 1 Baja Califomia & 1741615 & 1702808 & 38807 & 2.23 & 328279 & 19.28 & 657941 & 38.64 \\
\hline 2 Baja Califomia Sur & 425517 & 409984 & 15533 & 3.65 & 70206 & 17.12 & 149956 & 36.58 \\
\hline 3 Sinaloa & 1389771 & 1346510 & 43261 & 3.11 & 303800 & 22.56 & 696665 & 51.74 \\
\hline 4 Sonora & 1464617 & 1411604 & 53013 & 3.62 & 281607 & 19.95 & 616538 & 43.68 \\
\hline Total regional & 5021520 & 4870906 & 150614 & 3.00 & 983891 & 20.20 & 2121101 & 43.55 \\
\hline \multicolumn{9}{|l|}{ Región 5 Noreste } \\
\hline 1 Chihuahua & 1391498 & 1341233 & 50265 & 3.61 & 261500 & 19.50 & 475075 & 35.42 \\
\hline 2 Coahuila & 1772618 & 1733590 & 39028 & 2.20 & 278571 & 16.07 & 652957 & 37.67 \\
\hline 3 Durango & 804613 & 771803 & 32810 & 4.08 & 188790 & 24.46 & 397307 & 51.48 \\
\hline 4 Nuevo León & 2508932 & 2420543 & 88389 & 3.52 & 530416 & 21.91 & 886340 & 36.62 \\
\hline 5 Tamaulipas & 1697868 & 1632724 & 65144 & 3.84 & 345070 & 21.13 & 742021 & 45.45 \\
\hline Total regional & 8175529 & 7899893 & 275636 & 3.37 & 1604346 & 20.31 & 3153700 & 39.92 \\
\hline
\end{tabular}

Fuente: : INEGI (2019a y 2019b). 
En cambio, el occidente muestra mayor capacidad económica, ya que la tasa de desocupación es la más baja del país (junto con el Sureste), con 0.3 puntos abajo del promedio; en la del sector informal es de -3.3 puntos y en la de informalidad laboral de -2.2 puntos. Para la región del sureste el punto débil es la tasa de informalidad laboral, ya que representa $70.5 \%$ de su población ocupada, en la cual participa con $29.3 \%$ las actividades empresariales con recursos de los hogares, la segunda más alta, después del Centro. En contraste, la tasa de desocupación es la más baja del país, con 2.9 por ciento.

En las zonas noroeste y noreste existe mayor equilibrio. En la primera, su aportación de personas ocupadas es ligeramente mayor que la de la PEA: $9.0 \%$ contra $8.9 \%$, lo cual repercute en que la tasa de desocupación sea la tercera con menor impacto, con 3.0 por ciento. Por otra parte, la tasa de ocupación en el sector informal es 7 puntos menor a la nacional, y en la de informalidad laboral, en 13 puntos. En el noreste, aparentemente el principal problema es la tasa de desocupación, porque es ligeramente mayor a la media nacional, pero la tasa de ocupación en el sector informal es inferior en 7 puntos y 16.7 en la de informalidad laboral, por lo tanto, es el mercado laboral con mejores perspectivas de desarrollo.

\subsection{Empleo formal}

El principal reto para el país es reducir la informalidad en las actividades empresariales y gubernamentales para incorporar un mayor número de trabajadores en el Instituto Mexicano del Seguro Social (IMSS) y otras instituciones de seguridad social. Al cierre de 2018, la mayor parte de los trabajadores registrados en el IMSS se sitúan en el centro y occidente, con 30.9 y $24.9 \%$; seguidos muy de cerca por el noreste con 20.9 por ciento. Las otras dos regiones suman menos de una cuarta parte (cuadro A.2 del anexo). Los cambios en el mercado formal no son del todo alentadores. Entre 2005 y 2018, se incorporaron al IMss más de 7 millones, cantidad que no satisface la demanda laboral al atender $59.6 \%$ del incremento de la PEA y $76.7 \%$ del de los trabajadores subordinados y remunerados (cuadro A.3 del anexo).

La zona que, aparentemente, ha tenido mayor cobertura es la del centro, solo que ésta deriva de la alta concentración del empleo formal registrado en la Ciudad de México. Las cifras son confusas, porque las plazas creadas durante este periodo, son superiores al incremento de 
la PEA y los trabajadores subordinados, y aun así la capital del país tuvo una tasa anual de desocupación en 2018 de 5.3\%, más de 2 puntos arriba de la media nacional. La cuestión es: ¿los registros de la Ciudad de México incluyen parte de los que corresponden al Estado de México e Hidalgo por formar parte de la gran Zona Metropolitana? Al respecto hay dos posibles respuestas.

i. La Encuesta de ocupación y empleo para cada entidad se calcula conforme a la residencia de los trabajadores, independientemente del lugar donde laboran. Si un trabajador de Coahuila resuelve sus necesidades de ocupación en Nuevo León u otra entidad, este trabajador se le suma al estado donde se realizó la encuesta (INEGI-STYPS, 2011: 4).

ii. En el caso de un trabajador asegurado con temporalidad permanente o eventual, se le registra por el sitio donde radica el centro de trabajo, no por el origen del trabajador. En lo que corresponde a los servicios médicos, que son parte de las prestaciones, el trabajador y su familia los pueden percibir en su lugar de residencia, u otra entidad federativa colindante.

De este modo, la Ciudad de México puede estar satisfaciendo las necesidades de empleo formal de personas provenientes de la Zona Metropolitana y de otras entidades, y no necesariamente de residentes de la propia ciudad. Bajo esta consideración, el Estado de México e Hidalgo no alcanzan a cubrir ni la mitad de los trabajadores subordinados que se han incorporado a los mercados a lo largo de 13 años. El Estado de México abarca 44.5\%, mientras que Hidalgo alrededor de una tercera parte. Aun así, en conjunto la región ha cubierto $88.1 \%$ de la demanda de trabajadores subordinados. La de occidente cubre $81.3 \%$, mientras que la noreste $78.2 \%$ y la noroeste 68.2 por ciento. La más rezagada es la del sureste con 53.0 por ciento. En el ámbito estatal, los de mayor cobertura al incremento de la demanda de trabajo subordinado son, aparte de la Ciudad de México, Querétaro, Nuevo León y Sinaloa, con más de 100.0 por ciento. Entre 99.0 y $70.0 \%$ se encuentran Aguascalientes, Quintana Roo, Chihuahua, Guanajuato, Jalisco y Zacatecas. Los de menor protección, entre 15.0 y $35.0 \%$, son en orden ascendente: Guerrero, Tlaxcala, Campeche, Nayarit, Oaxaca e Hidalgo.

Otra variable importante es la calidad del empleo formal. De los 7 millones de nuevas plazas registradas en el IMSs, $79.0 \%$ han sido permanentes, $18.7 \%$ eventuales urbanas y $2.3 \%$ eventuales en el campo 
(cuadro A.2 del anexo). Las plazas permanentes, que son las de mejor calidad, se crearon en las zonas de occidente y centro, con $29.4 \%$ y $29.0 \%$ de participación. A mayor detalle, en 5 entidades se concentró $44.1 \%$ del nuevo empleo. La Ciudad de México aportó 15.6\%, Jalisco 9.2\%, Estado de México 8.2\%, Guanajuato 6.8\% y Querétaro 4.4 por ciento. Fuera de estas regiones, solamente sobresalen Nuevo León con 9.7\% y, con proporciones de alrededor del 4.1 por ciento, Baja California y Chihuahua.

Cabe decir, que la participación del empleo permanente ante el eventual urbano ha perdido espacio. Entre 2005 y 2018 retrocedió 3.7 puntos porcentuales, al pasar de $89.5 \%$ a 85.8 por ciento. Las zonas con mayor impacto fueron las del occidente y centro que retrocedieron en 4.5 y 4.4 puntos, seguidas por la noroeste con 3.5, la sureste con 2.7 y la noreste 2.2 puntos (cuadro A.4 del anexo). Únicamente 4 entidades avanzaron en participación, tres del sureste: Campeche, Oaxaca y Tabasco y una del occidente, Nayarit.

En contraparte, el empleo eventual avanzó 3 puntos. En el centro y occidente aumentaron 4.4 y 3.4 puntos; en el sureste 3 puntos y en el noreste 2.1; la de menor avance fue la del noroeste con 0.7 puntos.

La pérdida de calidad en el empleo, aunado a los altos índices de informalidad en las actividades empresariales y en general de la economía, explican en parte el lento crecimiento de las regiones y el bajo nivel de productividad, particularmente en el centro y sureste del país (Camargo, 2017: 137 y 140). Acentúa la situación el auge de la subcontratación, que compite los espacios al empleo remunerado.

\subsection{Empleo remunerado y no remunerado}

En 2003, el trabajo remunerado, que es el que genera valor agregado, representaba $65.0 \%$ del personal ocupado del país; diez años después, se redujo 8 puntos y medio. Las zonas más afectadas fueron las dos del norte y centro con 9 puntos cada una, con 8 la del sureste y con alrededor de 7 puntos, la de occidente. Por entidades, las de mayor impacto, con reducciones mayores a 10 puntos, fueron: Estado de México, Tlaxcala y Puebla en el centro; Quintana Roo y Yucatán en el sur; Querétaro en el occidente; Baja California Sur, Sinaloa, Chihuahua y Coahuila en el norte.

En cambio, el personal no remunerado avanzó alrededor de medio punto (de $26.5 \%$ del personal ocupado a $26.9 \%$ ), al mismo tiempo que 
el número de personas varió al doble de lo que creció el trabajo asalariado: $35.0 \%$ contra 15.6 por ciento. Nuevamente el centro fue el más golpeado, ya que aumentó 1 punto en participación y a un ritmo por arriba de la media (35.4\%), mientras el empleo remunerado se movió a menor velocidad (12.5 por ciento). A esto hay que sumar, que la zona contiene más de un tercio del personal no remunerado del país. Todos estos aspectos reducen la capacidad para elevar su valor agregado y productividad.

Salvo el sureste, las demás zonas redujeron la participación del personal no remunerado respecto al total del personal ocupado; sin embargo, las variaciones en términos absolutos fueron mayores a la del centro, entre $38.2 \%$ y $37.3 \%$, salvo el noreste que aumentó en 21.0 por ciento. Por entidades, las de mayor crecimiento, entre 57.8 y $50.0 \%$, fueron Querétaro, Baja California Sur, Tlaxcala, Chiapas, Yucatán, Oaxaca e Hidalgo; las de menor aumento: Tamaulipas, Coahuila, Ciudad de México y Nuevo León, con un rango que va de 15.0 a 20.7 por ciento.

\subsection{Contratación por la vía del outsourcing e impacto económico}

El suministro de personal por otra razón social ha sido muy alto a lo largo de una década; tan es así, que ninguna región y entidad federativa ha quedado al margen de utilizar este esquema a gran escala. En promedio, en el país aumentó en $200.0 \%$; por arriba de este porcentaje se encuentran el noroeste con $307.2 \%$ y el sureste con 243 por ciento. Al interior de la primera región sobresalen Baja California Sur (con 521.0\% de aumento) y Baja California (330.0\%). Lo que sorprende en la segunda zona es que el outsourcing ha servido para ampliar los espacios de informalidad en las entidades con mayor pobreza y rezago económicos: en Chiapas aumentó cerca de $400.0 \%$ y en Oaxaca $330.0 \%$, a la que se agrega Tabasco, un estado con menores necesidades, con $370.0 \%$.

Tanto en el noreste como en el occidente, la subcontratación aumentó conforme al promedio, en $208.6 \%$ y $204.0 \%$, pero hay estados con variaciones por arriba del $300.0 \%$, como Guanajuato, Michoacán y Querétaro. En el noreste ninguna entidad creció arriba de 300.0\%, incluso, tiene a la entidad con menor incremento en el país, Durango, con $75.5 \%$. La zona con menor variación es la del centro con $168.1 \%$; su desventaja es que en términos absolutos es la de mayor participación, 
con $38.0 \%$ en 2013. Las otras zonas con fuerte peso son la del noreste y occidente con alrededor de $20.0 \%$ cada una, el sureste con $13.0 \%$ y el noroeste con 9.1 por ciento. Las entidades con mayor proporción son: Ciudad de México (22.7\%), Estado de México (9.8\%), Nuevo León $(8.7 \%)$ y Jalisco $(7.1 \%)$, que tienen a las economías de mayor tamaño en el país. Las cuatro suman $48.4 \%$ del personal subcontratado.

Otra forma de observar el avance del outsourcing es a través de los pagos realizados a empresas dedicadas a la subcontratación, que en una década aumentaron $163.7 \%$ en términos reales, mientras que la masa salarial, en 10.1 por ciento. Si los pagos a otra razón social se dividieran entre el número de personas subcontratadas, el ingreso medio sería mayor al obtenido por trabajador remunerado, con la diferencia de que el primero contribuye al incremento del consumo intermedio y el segundo al valor agregado. En 2003 el hipotético ingreso por persona subcontratada hubiese sido de 142 mil pesos anuales y de 110 mil pesos en el remunerado, con una diferencia de $29.2 \%$ a favor del primero. Diez años después, los ingresos correspondientes serían de 124 mil 465 pesos contra 104 mil 686 pesos, con una variación entre uno y otro de $18.9 \%$. En ambos casos, el ingreso real habría caído $12.4 \%$ en el empleo subcontratado, atribuible también al aumento del número de personas bajo este esquema, y $4.8 \%$ en el empleo remunerado.

En la realidad, el hipotético ingreso medio del personal subcontratado es menor al que percibe el trabajador subordinado. Según el INEGI (2016b: 5) en 2013 el salario medio de aquel tipo de trabajador fue de 97 mil 900 pesos anuales, en tanto que el del remunerado fue de 114 mil 300 pesos (a precios de 2013), es decir, el del primero fue $14.3 \%$ menor. Además, el costo medio por persona suministrada fue de 136 mil pesos, lo que significa que la empresa de outsourcing gana $38.9 \%$ más de lo que paga a un trabajador que subcontrata. El planteamiento es: ¿Para qué admitir este tipo de empresa intermediaria, si fomentando a las que directamente contratan a trabajadores, contribuirían a incrementar el valor agregado, la productividad y la calidad de vida de las familias?

A nivel regional, los mayores incrementos en los pagos a otra razón social se observan en el noroeste y sur, con $221.7 \%$ y $217.9 \%$; decreciendo a $184.5 \%$ en el occidente, a $171.0 \%$ en el noreste y a $138.4 \%$ en el centro del país. Los mayores aumentos corresponden en su mayoría a entidades pobres: Oaxaca con 340.8\%, Chiapas 342.2\%, Tlaxcala 
351.5\%, Michoacán 364.1\%, Baja California Sur 592.7\%, Zacatecas $622.7 \%$ y Tabasco 755.4 por ciento.

Como proporción del gasto total, de los gastos por bienes y servicios y del consumo intermedio, los pagos a otra razón social avanzaron principalmente en el centro del país, con 0.10 puntos respecto al promedio, 0.43 puntos y 0.28 puntos. El sureste fue el de menor crecimiento (cuadro A.5 del anexo).

Al final, el mayor impacto del outsourcing es que ha contribuido al desequilibrado del VA frente al CI en el valor del producto final regional. El avance de cada componente lo indica todo: el primero aumentó en $17.4 \%$ y el segundo en 74.3 por ciento. El comportamiento del VA se explica parcialmente por el lento ritmo de la masa salarial, que en una década avanzó 10.0 por ciento. La zona con menor movimiento fue la del centro, con $1.4 \%$, lo cual manifiesta una razón más de su declive productivo. El noreste tampoco rebasó la media, al alcanzar 7.0 por ciento. Los mayores logros están en el sureste, con $31.6 \%$, seguido del occidente con $20.0 \%$ y el noroeste con 17.2 por ciento.

\subsection{Remuneraciones y productividad laboral}

Ante un acompasado crecimiento de la masa salarial y uno relativamente mayor del personal remunerado, el salario medio cayó en 4 regiones a lo largo de una década, a excepción del sureste que varió en 11.7 por ciento. En promedio, el ingreso medio disminuyó 4.8\%; el mayor golpe fue en la región centro, con $-9.9 \%$, seguida por la del noroeste con $-4.3 \%$, noreste con $-3.1 \%$ y occidente con -1.0 por ciento. De las 32 entidades, sólo un tercio aumentó el salario; sobresalen Tabasco con $88.6 \%$, Campeche con 22.6, Veracruz con 7.6, Chihuahua 5.9, Yucatán y San Luis Potosí con 5.5 y Tamaulipas con 4.1 por ciento. En contraste, los de mayores caídas fueron: Guerrero (16.0\%), Colima (17.6\%), Estado de México (12.4\%), Ciudad de México (11.5\%) y Nuevo León (11.2\%).

Como proporción del va, las remuneraciones totales también retrocedieron. En diez años, la participación pasó de una cuarta parte a 23.3 por ciento. Las zonas más afectadas fueron el noroeste con 3.6 puntos, la noreste con 2.7 y la del centro con 2 puntos. En el occidente y sur, el avance fue marginal, con 0.3 y 0.4 puntos porcentuales.

Ante el lento crecimiento de la masa salarial y la caída del salario real, la productividad laboral (VA por persona remunerada) solo 
aumentó $2.0 \%$ a lo largo de una década. Sin excepción, todas las regiones bajaron su margen; los incrementos se dieron localmente. Los mayores retrocesos fueron en el centro y occidente, con $18.4 \%$ y 13.8 por ciento. A menor ritmo, el sur con $-7.3 \%$, el noroeste con $-4.9 \%$ y el noreste con -3.2 por ciento. En el centro ninguna entidad aumentó el rendimiento laboral. En el sur fueron tres: Veracruz con $171.8 \%$, seguida de Tabasco y Yucatán; en el occidente están Colima (99.0\%), Zacatecas y San Luis Potosí; en el noroeste: Sonora (48.2\%), Baja California Sur y Sinaloa; y finalmente, en el noreste: Chihuahua (30.5\%), Durango, Tamaulipas y Nuevo León.

Aunque son pocas las entidades con niveles de productividad por arriba del promedio, el factible que el incremento salarial pueda ampliarse a otras. Todo depende de qué tanto haya disminuido el costo unitario de la mano de obra.

\subsection{Productividad del personal remunerado y costo unitario}

En términos generales, el incremento de la productividad laboral en México ha sido mayor al del costo unitario por persona remunerada, aspecto que hace posible, en principio, modificar el enfoque de utilizar a la política salarial como ancla para estabilizar el proceso inflacionario, y para escalar la competitividad de las empresas. En promedio, entre 2003 y 2013 , el CuMo disminuyó en $2.4 \%$ anual, a la vez que la productividad por unidad de trabajo aumentó $2.1 \%$, y $6.4 \%$ por hora trabajada. En todas las regiones la productividad por hora fue mayor a la productividad por unidad de trabajo (cuadros A.6 y A.7 del anexo).

En general, la productividad laboral se ha sustentado en el incremento del VA, que durante el periodo en promedio aumentó en $9.9 \%$ anual; la variación se encuentra por encima a la del personal remunerado $(7.5 \%)$ y a la de las horas trabajadas (4.2 por ciento). En el mismo sentido, el avance de la masa salarial fue menor al crecimiento de la producción, al ubicarse en 5.0\%; sin embargo, esto afectó a las remuneraciones medias por trabajador, que se redujeron en $2.35 \%$, casi en el mismo rango en que disminuyó el costo unitario $(2.39 \%)$. Caso contrario se dio en las remuneraciones por hora trabajada, ya que aumentaron en $1.2 \%$, elevando la productividad a 6.4 por ciento.

En todos los ámbitos, el incremento de la productividad laboral y del valor agregado fue mayor al de las otras variables, lo que mantiene 
la posibilidad de elevar los salarios o la cantidad de trabajadores de acuerdo con el desenvolvimiento de cada región.

\subsubsection{Por unidad de trabajo}

El centro del país es el que tiene los mayores retos en términos de productividad laboral porque en el periodo disminuyó en 3.1\%, al tiempo que el costo unitario aumentó en 1.9 por ciento (cuadro A.5 del anexo). De igual forma, el ritmo del producto, de $3.3 \%$, fue menor al de la masa salarial (3.8\%) y al del número de trabajadores $(6.7 \%)$, lo que originó la caída de las remuneraciones medias en $2.9 \%$, y de la propia productividad.

A excepción del sureste, las otras zonas tienen espacio para ampliar y mejorar el mercado laboral, porque a la vez que aumentaron la productividad, disminuyeron el CUMO. Las mejores condiciones están en el occidente, donde el rendimiento se elevó $7.6 \%$ y el costo bajó $2.7 \%$, lo mismo que la remuneración media cayó cerca de 1.0 por ciento. De igual forma, el ritmo de producción está por encima del incremento del número de trabajadores y de la masa salarial. La segunda región con potencial es la del noroeste, el ritmo de la productividad varió $4.3 \%$ anual y el cumo disminuyó 4.1 por ciento. En el mismo sentido, la producción se incrementó $18.3 \%$ en tanto que en el número de trabajadores fue de $12.0 \%$ y en la masa salarial de 11.2 por ciento. En la zona noreste, la productividad aumentó $4.1 \%$ y el cumobajó 2.9 por ciento. La producción, por su parte, creció $8.1 \%$, mientras que la cantidad del insumo laboral y la masa de remuneraciones fue a menor velocidad: $4.5 \%$ y 4.2 por ciento, lo que manifiesta con claridad la capacidad económica para mejorar el salario o ampliar el número trabajadores.

\subsubsection{Por hora trabajada}

La ventaja de analizar la productividad por hora trabajada es que es más específica que por unidad de trabajo. En este enfoque, aumentó en promedio $6.4 \%$ anual, mientras que el CuMo retrocedió $2.4 \%$. De igual forma, las horas trabajadas y la masa salarial se incrementaron a menor ritmo que el valor de la producción, lo que contribuyó a elevar la productividad. Las dos primeras variables crecieron $4.2 \%$ y $5.0 \%$, mientras que la tercera, casi 10.0 por ciento. Esta rentabilidad abre la posibilidad de aumentar el ingreso de los trabajadores o el número de 
plazas, sin perturbar la estabilidad macroeconómica (cuadro A.7 del anexo).

Bajo este esquema, la productividad es favorable en todas las regiones, aunque los CUMO variaron en poco monto, a excepción del centro del país. En ésta, la productividad se incrementó de forma marginal, en $0.2 \%$; en cambio, los costos laborales se multiplicaron por 10 y las remuneraciones medias aumentaron en 0.4 por ciento. La variación en el producto fue menor que en el número de horas trabajadas y la masa salarial, lo cual reduce las posibilidades para mejorar los salarios.

De las 4 regiones restantes, la de mayor capacidad para ampliar el mercado de trabajo es la de occidente, la productividad aumentó $13.7 \%$ y el CuMo disminuyó 2.7. Adicionalmente, es la de mayor incremento en el vA, con más de $20.0 \%$ anual. En el noroeste, la productividad aumentó $7.2 \%$, a la vez que el cumo se redujo en 2.4 por ciento. Finalmente, en el sureste la productividad está por encima del incremento en los costos: $14.0 \%$ contra 13.3 por ciento. De igual manera, la variación en el valor de la producción es mayor que la de las horas trabajadas y de la masa salarial, lo que hace factible el aumento de los ingresos de los trabajadores.

En suma. Las regiones con mejores condiciones laborales y con potencial capacidad para ampliar el mercado, son el occidente y norte del país. La alta productividad por persona ocupada o por hora trabajada, las hace rentables ante la caída de los costos laborales y la expansión del valor de la producción.

\section{CONCLUSIONES}

La reactivación del empleo remunerado y el incremento de los salarios y prestaciones son acciones necesarias para dejar atrás el acompasado comportamiento del producto interno bruto y el bajo margen de productividad en México y sus regiones sin atentar a la competitividad de las empresas y la estabilidad de precios. Bajo el enfoque de la productividad total de los factores se observa que la economía mexicana es insuficientemente competitiva porque la contribución de los factores productivos gestores de valor, particularmente el del trabajo, ha sido cada vez menor ante los insumos utilizados para la producción, de tal manera que el rendimiento de la economía ha retrocedido tras la crisis financiera de 2009. Considerando que los servicios, en donde actúa la 
subcontratación de personal, son los que presionan la productividad total y amplía la informalidad en los mercados, es pertinente desalentar su presencia. Un dato es la clave. Si entre 2011 y 2017, su contribución es superior en 0.08 puntos porcentuales a la del factor laboral, y coloca la PTF en $-0.10 \%$ anual, con reducir parte esta diferencia, que se duplica en la proporción, la economía mexicana no solo incrementaría el valor de la producción sino también su rendimiento, que pasaría a signo positivo.

En el segundo enfoque, en donde se evalúa, primero, la variación de la productividad ante la remuneración media y el cUMO por unidad de trabajo u hora trabajada, y después, la variación del producto con respecto al ritmo de la masa salarial, puestos de trabajo u horas laboradas, los resultados indican que, contrario a lo que se propaga y legitima la estabilidad y restricción del salario, la productividad laboral ha crecido por encima del ritmo salarial a costos cada vez menores. De igual forma, señala que la variación del producto es superior a lo que aumenta la masa salarial, los puestos de trabajo y las horas de trabajo, lo que favorece la rentabilidad del factor trabajo.

En ambos escenarios, la economía mexicana está en condiciones de ampliar el empleo remunerado e incrementar los salarios y prestaciones, sin presionar el índice de precios. Avanzar en este sentido, implicaría dar un paso adelante a favor de un sistema promotor del crecimiento económico sustentado en la productividad que, por un lado, alentaría la inversión, la intensificación del capital y la calidad del empleo; y por otra, incrementaría la demanda y el acceso a una canasta mayor de bienes y servicios, con lo cual mejoraría el bienestar social. En todo sentido, el crecimiento económico y el bienestar pasan necesariamente por la expansión del trabajo remunerado.

En las regiones y entidades federativas, el potencial de cada una depende de la situación de su mercado laboral. El estudio indica que ningún estado ha escapado del deterioro de su nivel de integración productiva, lo cual obedece, parcialmente, a la ausencia de políticas públicas enfocadas a favorecer el incremento del va y la productividad mediante el ensanchamiento de los espacios del trabajo remunerado y del ingreso. De igual forma, los costos laborales a la baja muestran la factibilidad de escalar los techos establecidos. Desde esta perspectiva, las zonas que actúen sobre la productividad del factor trabajo podrán mejorar sus niveles de competitividad. Las zonas con mayores retos son 
las centro y sur del país. Para renovar la calidad del crecimiento económico es necesario impulsar, al menos, tres acciones en esta materia.

- Cerrar los espacios a la informalidad laboral, induciendo el empleo directo en las empresas, acompañado de seguridad y prestaciones. Ello implica la reducción del empleo eventual, de la subcontratación de personal y de la ocupación no remunerada, a fin de expandir el producto, el ingreso medio y la productividad.

- Corregir los límites impuestos a las remuneraciones de los trabajadores para promover el bienestar y reducir con mayor eficacia los estratos de pobreza y la vulnerabilidad originada por carencias sociales y por ingreso, $y$

- Fomentar la productividad y el ingreso real para ampliar la demanda agregada, e impulsar, a la vez, el empleo y el rendimiento del capital. Ello supone la apertura de oportunidades para la educación y la capacitación como instrumentos para ampliar y actualizar las habilidades y capacidades del capital intelectual. El aspecto central continúa siendo la expansión del capital, solo que acotado a una mayor asignación de los beneficios obtenidos en la actividad productiva con base en la mejora continua del factor trabajo. Ello implica restituir la relación entre productividad, empleo y salarios para estimular la demanda agregada, establecer compromisos para mejorar la calidad del empleo y el incremento de los salarios reales, además de reposicionar a las remuneraciones al trabajo como factor importante para incrementar la producción y la competitividad.

\section{BIBLIOGRAFÍA}

Altamirano Estrada, Alfonso y Fernando Camargo Pérez (2012). "Desafios y propuestas para el desarrollo de la industria manufacturera del Estado de México", Secretaría de Desarrollo Económico, Fondo Editorial Mexiquense; Toluca, México.

Barranco, Alberto (2017). "Regular el outsourcing", El Universal, México, 17 de febrero. <http://www.eluniversal.com.mx/entrada-de-opinion/columna/alberto-barranco/cartera/2017/02/17/regulan-el-outsoursing $>\left[\begin{array}{ll}17 & \mathrm{de}\end{array}\right.$ febrero de 2017].

Camargo Pérez, Fernando (2013). "Reformas al mercado laboral para estimular la productividad, competitividad y la calidad de vida en el Estado de México", Cofactor, año 4, núm. 7, enero-junio, Toluca, México, pp. 7-93. 
Camargo Pérez, Fernando (2017). "Dinámica de la producción regional en México", Paradigma Económico, año 9 Núm. 2, julio-diciembre, México, Facultad de Economía, Universidad Autónoma del Estado de México, pp. 127-166, <https://hemeroteca.uaemex.mx/index.php/paradigmaeconomico> (14 de enero de 2019).

Camargo Pérez, Fernando (2019). "La vocación productiva del Estado de México, sus regiones y municipios", inédito, p.p. 17.

Centro de Estudios de las Finanzas Públicas (2007). "Propuesta PEF 2008 para Gasto Regional”, México, Cámara de Diputados, LX Legislatura.

Centro de Estudios Sociales y de Opinión Pública (2016). "Diagnóstico y propuesta para el desarrollo regional en México", Cámara de Diputados, LVIII Legislatura México. <CESOP-IL-14-DT223DesarrolloRegionaldeMexico-17082016.pdf $>$ [18 de febrero de 2017].

Consejo Nacional de Evaluación de la Política de Desarrollo Social - CONEVAL (2019). "Medición de pobreza 2008-2018", Consejo Nacional de Evaluación de la Política de Desarrollo Social. México. <https://www. coneval.org.mx/Medicion/MP/Paginas/Pobreza-2018.aspx $>$ [05 de agosto de 2019].

El Financiero (2018). Legisladores van por ajustes en outsourcing.

Flores, Zenyazen (2018). "SAT 'lee la cartilla' a firmas de outsourcing", El Financiero, México, 25 de febrero.

Gascón, Verónica (2015). "Prolifera outsourcing informal", Reforma, México, 10 de agosto.

Hoffer, Frank y Friederiker Spiecker (2011). "Europa, cambiarla o perderla", Existe una alternativa. Políticas y estrategias laborales más allá de la corriente dominante, OIT, Ginebra, Suiza, pp. 49-55.

Inegi (Instituto Nacional de Estadística y Geografía) (2014a). Productividad total de los factores bajo el modelo KLEMS, 1990-2011 (presentación), Instituto Nacional de Estadística y Geografía, Aguascalientes, México, agosto.

Inegi (2014b). Censos Económicos 2009. Conceptos, Instituto Nacional de Estadística y Geografía, México, mayo.

Inegi (2015 a). Glosario de los Censos Económicos 2014, Instituto Nacional de Estadística y Geografía, Aguascalientes, México.

Inegi (2015 b). Resultados definitivos de los Censos económicos, 2004, 2009 y 2014, Instituto Nacional de Estadística y Geografía. <http://www.beta. inegi.org.mx/app/saic/default.aspx $>$ [22 de julio de 2015].

Inegi (2016a). Cálculo de los índices de productividad laboral y del costo unitario de la mano de obra 2015, Instituto Nacional de Estadística y Geografía. Aguascalientes, México. $<\mathrm{http}$ ://internet.contenidos.inegi.org.mx/ contenidos/Productos/prod_serv/contenidos/espanol/bvinegi/productos/ nueva_estruc/702825078829.pdf $>$ [16 de abril de 2016].

Inegi (2016b). Resultados CE 2014 [presentación], Instituto Nacional de Esta- 
dística y Geografía. Aguascalientes, México.

Inegi (2017a). Sistema de Cuentas Nacionales de México. Fuentes y metodologías. Año base 2013. Productividad total de los factores modelo KLEMS. Instituto Nacional de Estadística y Geografía. <https://www.inegi.org. $\mathrm{mx} /$ contenidos/proyectos/cn/2013/ptf/metodologias/SCNM_Metodo_ KLEMS_B2013.pdf> [19 de diciembre de 2018].

Inegi (2017 b). Sistema de Cuentas Nacionales de México. Fuentes y metodologías. Producto interno bruto por entidad federativa. Anual. Año base 2013, Instituto Nacional de Estadística y Geografía. Aguascalientes, México, $<$ http://www.inegi.org.mx/est/contenidos/proyectos/cn/pibe/tabulados.aspx $>$ [02 de noviembre de 2017].

Inegi (2018). SCNM: Productividad Total de los Factores Modelo KLEMS. Año Base 2013. Serie 1990-2017 (Preliminar), Instituto Nacional de Estadística y Geografía. <https:/www.inegi.org.mx/app/tmp/tabuladoscn/ default.html?tema=PTF $>$ [17 de diciembre de 2018].

Inegi (2019a). Encuesta nacional de ocupación y empleo al IV trimestre de 2018, Instituto Nacional de Estadística y Geografía. < https://www.inegi. org.mx/programas/enoe/15ymas/?init=1> [14 de febrero de 2019].

Inegi (2019b). Encuesta Nacional de Ocupación y Empleo. Indicadores estratégicos por entidad federativa al IV trimestre de 2018, Instituto $\mathrm{Na}-$ cional de Estadística y Geografía. <https://www.inegi.org.mx/programas/ enoe/15ymas/?init=1> [14 de febrero de 2019].

Inegi-AMIA (2016). Estadísticas a propósito de... la Industria automotriz, Instituto Nacional de Estadística y Geografía. Aguascalientes, México, $<$ http://www.beta.inegi.org.mx/app/publicaciones/ [25 de agosto de 2017].

Inegi-Secretaría del Trabajo y Previsión Social (2011). Encuesta nacional de ocupación y empleo: ENOE 2010, Aguascalientes, México, 52 pp.

$<$ http://internet.contenidos.inegi.org.mx/contenidos/Productos/prod_serv/contenidos/espanol/bvinegi/productos/histori$\cos / 2104 / 702825445072 / 702825445072$ _.pdf $>$ [05 de agosto de 2017].

Jackson, Andrew (2011). "Cuidado con el modelo de austeridad canadiense", Existe una alternativa. Políticas y estrategias laborales más allá de la corriente dominante, OIT, Ginebra, Suiza, pp. 35-40.

Janssen, Ronald (2011). "Gobernanza económica europea, el próximo gran atraco a los salarios", Existe una alternativa. Politicas y estrategias laborales más allá de la corriente dominante, OIT, Ginebra, Suiza, pp. 45-48.

Migueles, Rubén (2018). " $80 \%$ de empleo formal, bajo algún tipo de subcontratación”, El Universal, México <https://www.eluniversal.com.mx/ cartera/80-de-empleo-formal-bajo-algun-tipo-de-subcontratacion>, [25 de febrero de 2019].

Palley, Thomas (2011). “Aspectos económicos de la recuperación basada en salarios. Análisis y recomendaciones de política”, Boletín Internacional de Investigación Sindical, vol. 3, número 2, OIT, Ginebra, Suiza, pp. 243- 
271.

Piz, Víctor (2018). "La formalidad impulsa el avance del empleo", El Financiero, México, 14 de febrero, <https://www.elfinanciero.com.mx/search/ La\%20formalidad\%20impulsa\%20el\%20avance\%20del\%20empleo> [19 de febrero de 2018].

Porter, Michael E. (1991). La ventaja competitiva de las naciones, Argentina, Javier Vergara Editor.

Sánchez Medina, A. Melián González, A. y E. Hormiga Pérez. (2007). “El concepto de capital intelectual y sus dimensiones", Investigaciones europeas de dirección y economía de la empresa, Vol. 13, núm. 2, pp. 97-111.

Storm, Servaas y C.W.M Naastepad (2011). "Los efectos del crecimiento basado en los salarios sobre la productividad y las inversiones", Boletín Internacional de Investigación Sindical, vol. 3, número 2, OIT, Ginebra, Suiza, pp. 217-242.

Secretaría de Hacienda y Crédito Público - SHCP (2014). "Decreto por el que se otorgan estímulos para promover la incorporación a la seguridad social", Diario Oficial de la Federación, 08 de abril de 2014.

Secretaría de Programación y Presupuesto (SPP, 1981a). El ABC de las Cuentas Nacionales, México.

Secretaría de Programación y Presupuesto (1981b). Sistema de Cuentas Nacionales de México.

Secretaría del Trabajo y Previsión Social -STPS (2019). Estadísticas laborales, <http://www.stps.gob.mx/bp/secciones/conoce/areas_atencion/areas atencion/web/asegurados.htm $>$ [25 de febrero de 2019].

Standing, Guy (2017). “Las 5 mentiras más grandes del capitalismo global', World Economic Forum, 5 de enero, <https://es.weforum.org/agenda/2017/01/las-5-mentiras-mas-grandes-del-capitalismo-global $>$ [15 enero de 2018].

Van Treeck, Till (2011). “¿Por qué no funciona el Pacto de Estabilidad y Crecimiento?", Existe una alternativa. Políticas y estrategias laborales más allá de la corriente dominante, OIT, Ginebra, Suiza, pp. 41-44.

Weiguang, Chen (2011). "Sindicatos y luchas obreras en Guangdong”, Existe una alternativa. Políticas y estrategias laborales más allá de la corriente dominante, OIT, Ginebra, Suiza, pp. 21-26. 


\section{ANEXO}

Cuadro A.1

CONTRIBUCIÓN DE LOS FACTORES DE LA PRODUCCIÓN AL CRECIMIENTO DE MÉXICO, 1991-2017 (PARTICIPACIÓN PONDERADA ANUAL, \%)

\begin{tabular}{|c|c|c|c|c|c|}
\hline $\begin{array}{l}\text { Servicios de } \\
\text { Capital Total }\end{array}$ & $\begin{array}{c}\text { Servicios } \\
\text { laborales } \\
\text { totales }\end{array}$ & Energia & Materiales & Servicios & $\begin{array}{l}\text { Total de } \\
\text { bienes y } \\
\text { servicios }\end{array}$ \\
\hline \multicolumn{6}{|c|}{ Contribución de los factores al crecimiento de México } \\
\hline & & & \multicolumn{3}{|c|}{ Insumos intermedios } \\
\hline $\begin{array}{c}\text { Capital Total } \\
\text { (K) }\end{array}$ & Trabajo (L) & Energia ( $(E)$ & $\begin{array}{l}\text { Materiales } \\
\text { (M) }\end{array}$ & Servicios (S) & $\begin{array}{l}\text { Total } \\
\text { insumos }\end{array}$ \\
\hline 44.56 & 10.59 & 13.66 & 25.22 & 5.98 & 44.85 \\
\hline 44.61 & 15.66 & 3.15 & 24.76 & 11.82 & 39.73 \\
\hline 63.34 & 17.90 & 4.25 & 7.98 & 6.53 & 18.76 \\
\hline 33.77 & 9.68 & 7.12 & 37.49 & 11.95 & 56.55 \\
\hline-20.02 & 13.24 & 6.73 & 68.62 & 31.43 & 106.78 \\
\hline 1.42 & 15.92 & 5.96 & 71.89 & 4.82 & 82.66 \\
\hline 16.88 & 17.66 & 4.71 & 48.58 & 12.18 & 65.46 \\
\hline 30.40 & 8.69 & 7.86 & 43.30 & 9.75 & 60.91 \\
\hline 41.50 & 14.66 & -1.11 & 26.46 & 18.50 & 43.85 \\
\hline 38.54 & 4.47 & 3.67 & 42.14 & 11.18 & 56.99 \\
\hline 155.98 & 26.32 & -2.06 & -63.96 & -16.29 & -82.30 \\
\hline 91.71 & -6.46 & 5.70 & 13.66 & -4.61 & 14.75 \\
\hline 52.23 & 33.87 & 10.63 & -4.01 & 7.29 & 13.90 \\
\hline 29.20 & 21.56 & 4.69 & 33.25 & 11.30 & 49.24 \\
\hline 40.44 & 0.29 & -2.65 & 38.08 & 23.85 & 59.27 \\
\hline 29.08 & 12.34 & -0.69 & 44.44 & 14.82 & 58.58 \\
\hline 47.09 & 13.26 & -3.61 & 25.28 & 17.99 & 39.65 \\
\hline 92.36 & 19.76 & 2.49 & -9.78 & -4.83 & -12.12 \\
\hline-50.33 & 14.63 & 5.85 & 111.35 & 18.50 & 135.70 \\
\hline 23.11 & 7.79 & -5.00 & 62.29 & 11.82 & 69.11 \\
\hline 45.47 & 15.27 & -4.91 & 22.21 & 21.96 & 39.26 \\
\hline 43.10 & 13.73 & 3.28 & 21.22 & 18.67 & 43.17 \\
\hline 84.10 & 15.89 & 11.24 & -1.49 & -9.74 & 0.01 \\
\hline 43.54 & 6.96 & -24.35 & 52.31 & 21.54 & 49.50 \\
\hline 46.65 & 9.46 & -30.38 & 34.45 & 39.83 & 43.89 \\
\hline 61.64 & 12.95 & 10.26 & 24.21 & -9.06 & 25.41 \\
\hline 46.40 & 9.61 & -6.86 & 48.89 & 1.96 & 43.99 \\
\hline
\end{tabular}

Fuente: INEGI (2018). SCNM: Productividad Total de los Factores Modelo KLEMS. 
Cuadro A.2

MÉXICO. TRABAJADORES REGISTRADOS EN EL IMSS POR CATEGORÍA Y REGIÓN, 2005 Y 2018

\begin{tabular}{|c|c|c|c|c|}
\hline \multirow[b]{2}{*}{ ENTIDAD NACIONAL } & \multicolumn{4}{|c|}{2005} \\
\hline & Total & Permanente & $\begin{array}{c}\text { Eventual } \\
\text { Urbano }\end{array}$ & $\begin{array}{c}\text { Eventual en } \\
\text { el Campo }\end{array}$ \\
\hline & 13061565 & 11684599 & 1286702 & 90264 \\
\hline \multicolumn{5}{|c|}{ Región 1 Centro Pais } \\
\hline 1 Ciudad de México & 2307721 & 2103930 & 203791 & - \\
\hline 2 Hidalgo & 143175 & 122757 & 19616 & 802 \\
\hline 3 México & 1030654 & 899292 & 131159 & 203 \\
\hline 4 Morelos & 156024 & 138337 & 15250 & 2437 \\
\hline 5 Puebla & 394036 & 353424 & 40089 & 523 \\
\hline 6 Tlaxcala & 71162 & 64831 & 6319 & 12 \\
\hline Total reglonal & 4102772 & 3682571 & 416224 & 3977 \\
\hline \multicolumn{5}{|l|}{ Región 2 Sur Sureste } \\
\hline 1 Campeche & 105758 & 83479 & 22035 & 244 \\
\hline 2 Chiapas & 157841 & 141129 & 15636 & 1076 \\
\hline 3 Guerrero & 135085 & 107582 & 26987 & 516 \\
\hline 4 Oaxaca & 154042 & 133874 & 16238 & 3930 \\
\hline 5 Quintana Roo & 215265 & 185092 & 28576 & 1597 \\
\hline 6 Tabasco & 128974 & 108286 & 20254 & 434 \\
\hline 7 Veracruz & 593757 & 502915 & 72793 & 18049 \\
\hline 8 Yucatán & 253470 & 235257 & 17765 & 448 \\
\hline Total regional & 1744192 & 1497614 & 220284 & 26294 \\
\hline
\end{tabular}

\begin{tabular}{rrrrr}
\multicolumn{4}{c}{2018} \\
\hline \multicolumn{1}{c}{ Total } & Permanente & $\begin{array}{c}\text { Eventual } \\
\text { Urbano }\end{array}$ & $\begin{array}{c}\text { Eventual en } \\
\text { el Campo }\end{array}$ \\
\hline 20079365 & 17229742 & 2597677 & 251946 \\
\hline 3410841 & 2966951 & 443890 & - \\
\hline 226929 & 180360 & 46336 & 233 \\
\hline 1627196 & 1354701 & 270771 & 1724 \\
\hline 212112 & 182598 & 26667 & 2847 \\
\hline 620188 & 526566 & 88236 & 5386 \\
\hline 100979 & 76794 & 23476 & 709 \\
\hline 6198245 & 5287970 & 899376 & 10899 \\
\hline
\end{tabular}

Región 3 Centro Occidente

\begin{tabular}{|l|l|l|l|l|}
\hline Aguascalientes & 187024 & 171327 & 14655 & 1042 \\
\hline
\end{tabular}

$\begin{array}{lllll}2 \text { Colima } & 88116 & 73885 & 12470 & 1761\end{array}$

\begin{tabular}{|l|r|r|r|r|r|}
\hline 3 & Guanajuato & 537799 & 484348 & 50589 & 2862 \\
\hline
\end{tabular}

$\begin{array}{lllll}4 \text { Jalisco } & 1095746 & 992256 & 96336 & 7154\end{array}$

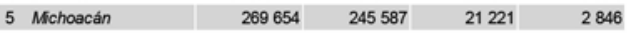

6 Nayarit $\quad 96465 \quad 74219 \quad 19741 \quad 2505$

\begin{tabular}{|l|r|r|r|r|r|}
7 & Querétaro & 272724 & 228009 & 42519 & 2196 \\
\hline
\end{tabular}

8 San Luis Potosi $\quad 263156 \quad 227024 \quad 32678 \quad 3454$

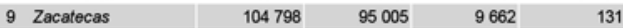

\begin{tabular}{|l|r|r|r|r|}
\hline Total regional & 2915482 & 2591660 & 299871 & 23951 \\
\hline
\end{tabular}

\begin{tabular}{|r|r|r|r|}
\hline 125280 & 102408 & 22157 & 715 \\
\hline 225667 & 200479 & 21819 & 3369 \\
\hline 157793 & 124757 & 32789 & 247 \\
\hline 215491 & 188619 & 23298 & 3574 \\
\hline 447348 & 323743 & 122788 & 817 \\
\hline 165576 & 139573 & 22443 & 3560 \\
\hline 752659 & 631920 & 103460 & 17279 \\
\hline 374432 & 337533 & 35788 & 1111 \\
\hline 2464246 & 2049032 & 384542 & 30672 \\
\hline
\end{tabular}

\section{Región 4 Noroeste}

\begin{tabular}{|l|l|l|l|l|l|}
\hline 1 & Baja Califomia & 600487 & 557776 & 38080 & 4631 \\
\hline
\end{tabular}

2 Baja Califomia Sur $\quad 101477 \quad 81601 \quad 15273 \quad 4603$

$293667-34035-12081$

\begin{tabular}{lllllr}
3 & Sinaloa & 339783 & 293667 & 34035 & 12081 \\
\hline & 408424 & 354699 & 45747 & 7978
\end{tabular}

\begin{tabular}{|l|r|r|r|r|}
\hline Total regional & 1450171 & 1287743 & 133135 & 29293 \\
\hline
\end{tabular}

Región 5 Noreste

\begin{tabular}{|c|c|c|c|c|c|c|c|c|}
\hline 1 Chihuahua & 496848 & 458193 & 38023 & 632 & 779580 & 689589 & 85673 & 4318 \\
\hline 2 Coahuila & 658136 & 620633 & 35436 & 2067 & 882868 & 803279 & 76024 & 3565 \\
\hline 3 Durango & 165840 & 153391 & 12289 & 160 & 243651 & 219431 & 23865 & 355 \\
\hline 4 Nuevo León & 996720 & 915396 & 80965 & 359 & 1608191 & 1453433 & 154265 & 493 \\
\hline 5 Tamaulipas & 531404 & 477398 & 50475 & 3531 & 674263 & 603252 & 68782 & 2229 \\
\hline Total regional & 2848948 & 2625011 & 217188 & 6749 & 4188553 & 3768984 & 408609 & 10960 \\
\hline
\end{tabular}

Fuente: STPS (2019). Estadísticas laborales.

\begin{tabular}{|r|r|r|r|}
\hline 321298 & 294190 & 25792 & 1316 \\
\hline 134121 & 109452 & 22043 & 2626 \\
\hline 994870 & 859332 & 126872 & 8666 \\
\hline 1761000 & 1501532 & 221339 & 38129 \\
\hline 447924 & 365743 & 56461 & 25720 \\
\hline 138808 & 107700 & 28141 & 2967 \\
\hline 576858 & 471421 & 102490 & 2947 \\
\hline 439816 & 355128 & 75203 & 9485 \\
\hline 185244 & 157235 & 27113 & 896 \\
\hline 4999939 & 4221733 & 685454 & 92752 \\
\hline
\end{tabular}

\begin{tabular}{|r|r|r|r|}
\hline 877445 & 804397 & 56657 & 16391 \\
\hline 181598 & 129199 & 39686 & 12713 \\
\hline 562199 & 449438 & 57524 & 55237 \\
\hline 607140 & 518989 & 65829 & 22322 \\
\hline 2228382 & 1902023 & 219696 & 106663 \\
\hline
\end{tabular}




\section{Cuadro A.3}

MÉXICO: VARIACIÓN ABSOLUTA DE LA PEA, DE TRABAJADORES SUBORDINADOS Y REMUNERADOS, Y TRABAJADORES REGISTRADOS EN EL IMSS POR REGIÓN, $2005-2018$

\begin{tabular}{|c|c|c|c|c|c|}
\hline ENTIDAD NACIONAL & PEA & $\begin{array}{l}\text { Trabajadores } \\
\text { Subordinados y } \\
\text { Remuenrados }\end{array}$ & I M S S & IMSS / PEA & $\begin{array}{c}\text { IMSS I } \\
\text { Trabajadores } \\
\text { Subordinados }\end{array}$ \\
\hline & 11777680 & 9154689 & 7017800 & 59. 59 & 76.66 \\
\hline \multicolumn{6}{|l|}{ Región 1 Centro Pais } \\
\hline 1 Ciudad de México & 214393 & 101250 & 1103120 & 514.53 & 1089.50 \\
\hline 2 Hidalgo & 297582 & 255281 & 83754 & 28.14 & 32.81 \\
\hline 3 México & 2076574 & 1341759 & 596542 & 28.73 & 44.46 \\
\hline 4 Morelos & 135512 & 118686 & 56088 & 41.39 & 47.26 \\
\hline 5 Puebla & 603060 & 457642 & 226152 & 37.50 & 49.42 \\
\hline 6 Tlaxcala & 143593 & 104269 & 29817 & 20.76 & 28.60 \\
\hline Total regional & 3470714 & 2378887 & 2095473 & 60. 38 & 88.09 \\
\hline \multicolumn{6}{|l|}{ Región 2 Sur Sureste } \\
\hline 1 Campeche & 100305 & 60937 & 19522 & 19.46 & 32.04 \\
\hline 2 Chiapas & 322411 & 117940 & 67826 & 21.04 & 57.51 \\
\hline 3 Guerrero & 342813 & 135851 & 22708 & 6.62 & 16.72 \\
\hline 4 Oaxaca & 275974 & 190899 & 61449 & 22.27 & 32.19 \\
\hline 5 Quintana Roo & 339176 & 263309 & 232083 & 68.43 & 88.14 \\
\hline 6 Tabasco & 228880 & 82616 & 36602 & 15.99 & 44.30 \\
\hline 7 Veracruz & 491097 & 294422 & 158902 & 32.36 & 53.97 \\
\hline 8 Yucatán & 288376 & 212127 & 120962 & 41.95 & 57.02 \\
\hline Total regional & 2389032 & 1358101 & 720054 & 30. 14 & 53.02 \\
\hline \multicolumn{6}{|c|}{ Región 3 Centro Occidente } \\
\hline 1 Aguascalientes & 152939 & 137389 & 134274 & 87.80 & 97.73 \\
\hline 2 Colima & 123093 & 91974 & 46005 & 37.37 & 50.02 \\
\hline 3 Guanajuato & 600303 & 584739 & 457071 & 76.14 & 78.17 \\
\hline 4 Jalisco & 803035 & 854305 & 665254 & 82.84 & 77.87 \\
\hline 5 Míchoacán & 307362 & 289422 & 178270 & 58.00 & 61.60 \\
\hline 6 Nayarit & 187960 & 131862 & 42343 & 22.53 & 32.11 \\
\hline 7 Querétaro & 152883 & 128733 & 304134 & 198.93 & 236.25 \\
\hline 8 San Luis Potosí & 253807 & 228785 & 176660 & 69.60 & 77.22 \\
\hline 9 Zacatecas & 108281 & 115606 & 80446 & 74.29 & 69.59 \\
\hline Total regional & 2689663 & 2562815 & 2084457 & 77. 5 & 81.33 \\
\hline \multicolumn{6}{|l|}{ Región 4 Noroeste } \\
\hline 1 Baja California & 506432 & 433184 & 276958 & 54.69 & 63.94 \\
\hline 2 Baja California Sur & 179033 & 141510 & 80121 & 44.75 & 56.62 \\
\hline 3 Sinaloa & 199898 & 216790 & 222416 & 111.26 & 102.60 \\
\hline 4 Sonora & 445429 & 350454 & 198716 & 44.61 & 56.70 \\
\hline Total regional & 1330792 & 1141938 & 778211 & 58. 48 & 68.15 \\
\hline \multicolumn{6}{|l|}{ Región 5 Noreste } \\
\hline 1 Chihuahua & 358587 & 324586 & 282732 & 78.85 & 87.11 \\
\hline 2 Coahuila & 404694 & 436402 & 224732 & 55.53 & 51.50 \\
\hline 3 Durango & 219134 & 182904 & 77811 & 35.51 & 42.54 \\
\hline 4 Nuevo León & 542349 & 477448 & 611471 & 112.74 & 128.07 \\
\hline 5 Tamaulipas & 372715 & 291608 & 142859 & 38.33 & 48.99 \\
\hline Total regional & 1897479 & 1712948 & 1339605 & 70. 6 & 78.20 \\
\hline
\end{tabular}

Fuente: STPS (2019) e INEGI (2019b). 
Cuadro A.4

VARIACIÓN EN LA PARTICIPACIÓN ESTATAL Y REGIONAL DE TRABAJADORES REGISTRADOS EN EL IMSS POR CATEGORÍA, 2005 - 2018 (PUNTOS

PORCENTUALES)

\begin{tabular}{|c|c|c|c|c|}
\hline ENTIDAD NACIONAL & Total & Permanente & Urbano & el Campo \\
\hline & 0.00 & -3.65 & 3.09 & 0.56 \\
\hline \multicolumn{5}{|l|}{ Región 1 Centro País } \\
\hline Ciudad de México & 0.00 & -4.18 & 4.18 & 0.00 \\
\hline Hidalgo & 0.00 & -6.26 & 6.72 & -0.46 \\
\hline 3 México & 0.00 & -4.00 & 3.91 & 0.09 \\
\hline Morelos & 0.00 & -2.58 & 2.80 & -0.22 \\
\hline 5 Puebla & 0.00 & -4.79 & 4.05 & 0.74 \\
\hline 6 Tlaxcala & 0.00 & -15.05 & 14.37 & 0.69 \\
\hline Total regional & 0.00 & -4.44 & 4.37 & 0.08 \\
\hline
\end{tabular}

\section{Región 2 Sur Sureste}

\begin{tabular}{|l|l|c|c|c|c|}
\hline 1 & Campeche & 0.00 & 2.81 & -3.15 & 0.34 \\
\hline 2 & Chiapas & 0.00 & -0.57 & -0.24 & 0.81 \\
\hline 3 & Guerrero & 0.00 & -0.58 & 0.80 & -0.23 \\
\hline 4 & Oaxaca & 0.00 & 0.62 & 0.27 & -0.89 \\
\hline 5 & Quintana Roo & 0.00 & -13.61 & 14.17 & -0.56 \\
\hline 6 & Tabasco & 0.00 & 0.34 & -2.15 & 1.81 \\
\hline 7 Veracruz & 0.00 & -0.74 & 1.49 & -0.74 \\
\hline 8 & Yucatán & 0.00 & -2.67 & 2.55 & 0.12 \\
\hline
\end{tabular}

\section{Región 3 Centro Occidente}

\begin{tabular}{|l|l|l|l|l|l|}
\hline 1 & Aguascalientes & 0.00 & -0.04 & 0.19 & -0.15 \\
\hline 2 & Colima & 0.00 & -2.24 & 2.28 & -0.04 \\
\hline 3 Guanajuato & 0.00 & -3.68 & 3.35 & 0.34 \\
\hline 4 Jalisco & 0.00 & -5.29 & 3.78 & 1.51 \\
\hline 5 & Michoacán & 0.00 & -9.42 & 4.74 & 4.69 \\
\hline 6 & Nayarit & 0.00 & 0.65 & -0.19 & -0.46 \\
\hline 7 Querétaro & 0.00 & -1.88 & 2.18 & -0.29 \\
\hline 8 San Luis Potosín & 0.00 & -5.53 & 4.68 & 0.84 \\
\hline 9 & Zacatecas & 0.00 & -5.78 & 5.42 & 0.36 \\
\hline$\quad$ Total regional & 0.00 & -4.46 & 3.42 & 1.03 \\
\hline
\end{tabular}

\section{Región 4 Noroeste}

\begin{tabular}{|l|l|l|l|l|l|}
\hline 1 & Baja California & 0.00 & -1.21 & 0.12 & 1.10 \\
\hline 2 & Baja California Sur & 0.00 & -9.27 & 6.80 & 2.46 \\
\hline 3 & Sinaloa & 0.00 & -6.48 & 0.22 & 6.27 \\
\hline 4 & Sonora & 0.00 & -1.36 & -0.36 & 1.72 \\
\hline & Total regional & 0.00 & -3.44 & 0.68 & 2.77 \\
\hline
\end{tabular}


Cuadro A.4 CONTINUACIÓN

\begin{tabular}{|c|c|c|c|c|}
\hline ENTIDAD NACIONAL & Total & Permanente & $\begin{array}{c}\text { Eventual } \\
\text { Urbano }\end{array}$ & $\begin{array}{c}\text { Eventual en } \\
\text { el Campo }\end{array}$ \\
\hline \multicolumn{5}{|l|}{ Región 5 Noreste } \\
\hline 1 Chihuahua & 0.00 & -3.76 & 3.34 & 0.43 \\
\hline 2 Coahuila & 0.00 & -3.32 & 3.23 & 0.09 \\
\hline 3 Durango & 0.00 & -2.43 & 2.38 & 0.05 \\
\hline 4 Nuevo León & 0.00 & -1.46 & 1.47 & -0.01 \\
\hline 5 Tamaulipas & 0.00 & -0.37 & 0.70 & -0.33 \\
\hline Total regional & 0.00 & -11.35 & 11.12 & 0.23 \\
\hline
\end{tabular}

Fuente: Con base en STPS (2019). 


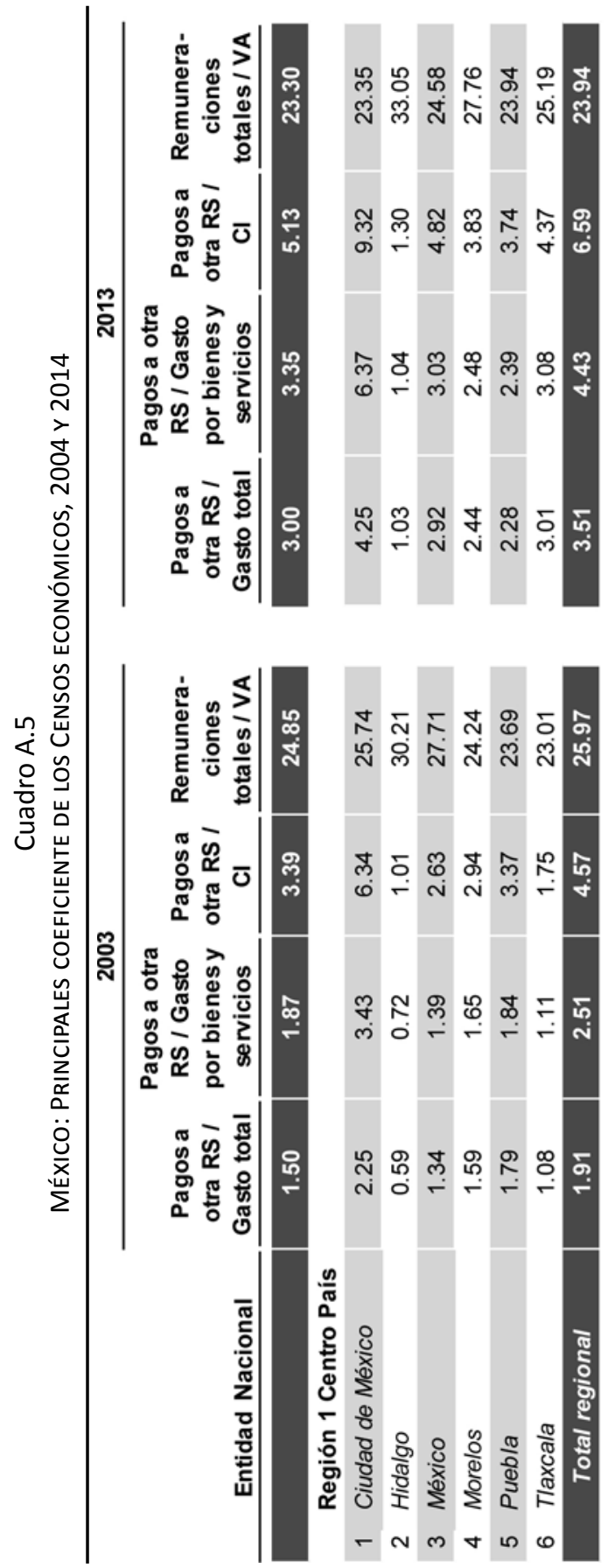

눙

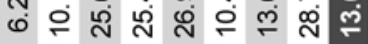

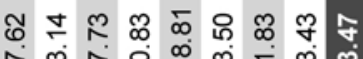

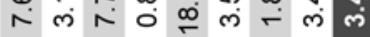

mi

กֶ.

ஜ

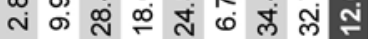

సิ

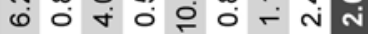

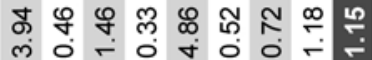

オ

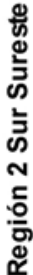

ค.

โ ฮึ ర 


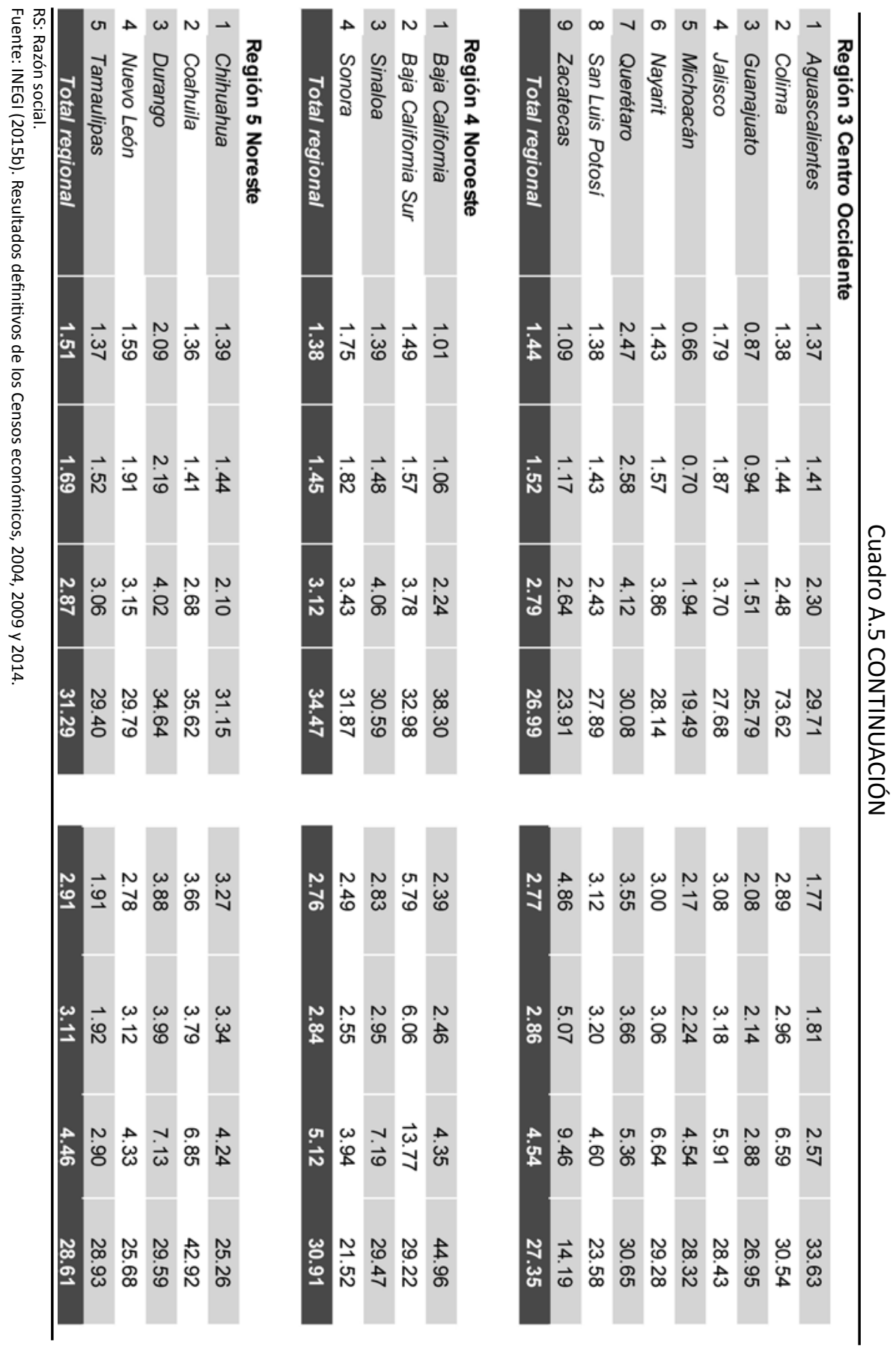


Paradigma económico $\rceil$ Año 11 Núm. 17 enero-junio 20197 ISSN: 2007-3062 7 pp. 101-134

Cuadro A.6

Regiones de MÉxico: PROductiVIDAd Y COSTO UNITARIO DE LA MANO DE OBRA POR Persona ReMunerada. Promedio 2003 - 2013 (VARIACIÓn ANUAL, 2008=100)

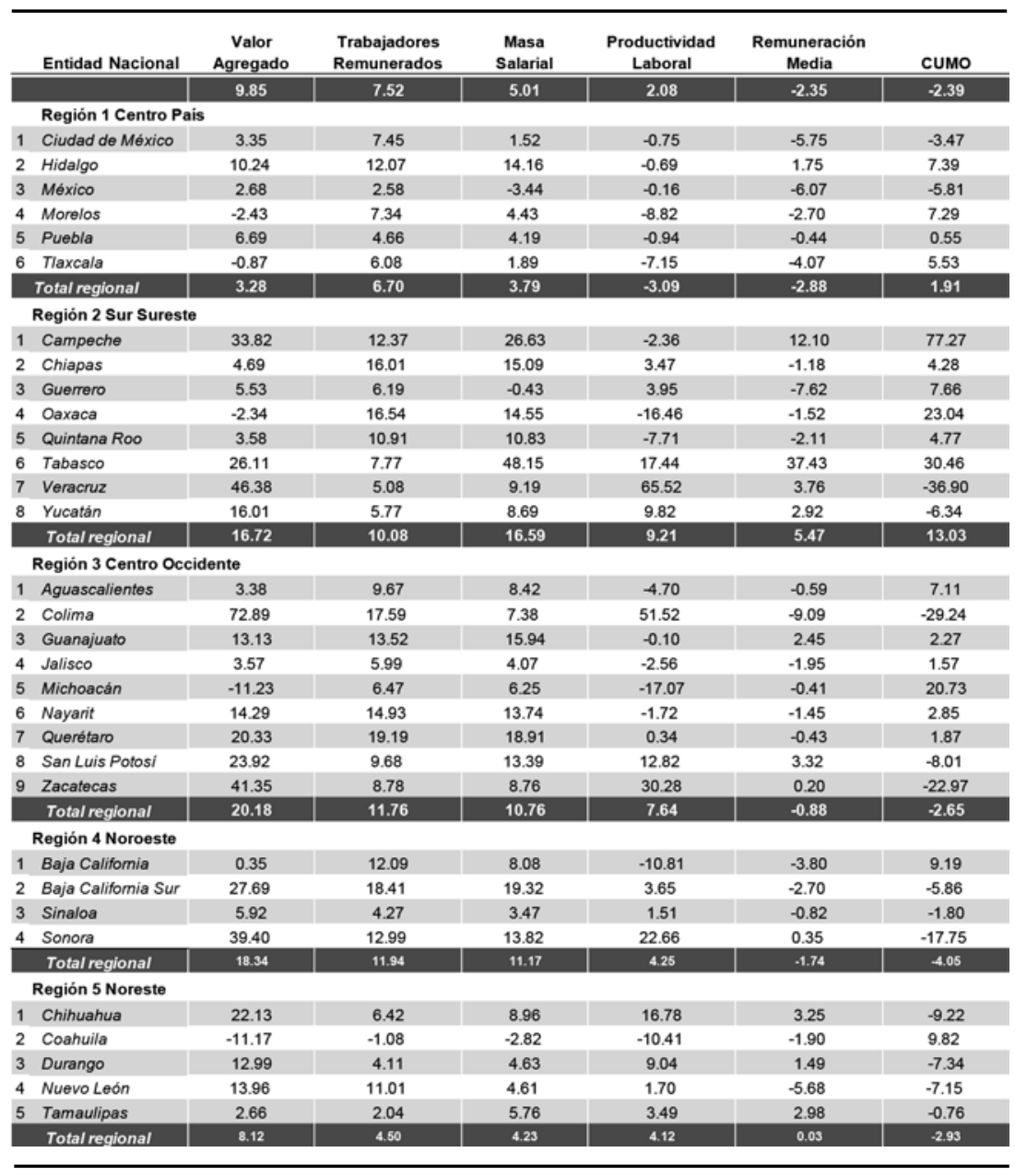

Fuente: INEGI (2015b). 
Cuadro A.7

Regiones de MÉxico: Productividad Y COSTO UNITARIO de LA MANO DE OBRA POR HORA tRABAJADA. PRomedio 2003 - 2013 (VARIACIÓN ANUAL, 2008=100)

\begin{tabular}{|c|c|c|c|c|c|c|}
\hline Entidad Nacional & $\begin{array}{c}\text { Valor } \\
\text { Agregado } \\
\end{array}$ & $\begin{array}{l}\text { Trabajadores } \\
\text { Remunerados }\end{array}$ & $\begin{array}{c}\text { Masa } \\
\text { Salarial } \\
\end{array}$ & $\begin{array}{c}\text { Productividad } \\
\text { Laboral }\end{array}$ & $\begin{array}{c}\text { Remuneración } \\
\text { Media }\end{array}$ & CUMO \\
\hline & 9.85 & 4.15 & 5.01 & 6.35 & 1.16 & -2.39 \\
\hline \multicolumn{7}{|c|}{ Región 1 Centro Pais } \\
\hline 1 Ciudad de México & 3.35 & 6.46 & 1.52 & -1.34 & -4.75 & -0.03 \\
\hline 2 Hidalgo & 10.24 & 7.22 & 14.16 & 2.73 & 6.51 & 7.39 \\
\hline 3 México & 2.68 & -0.29 & -3.44 & 3.27 & -2.91 & -5.81 \\
\hline 4 Morelos & -2.43 & 2.96 & 4.43 & -5.24 & 1.43 & 7.29 \\
\hline 5 Puebla & 6.69 & 1.83 & 4.19 & 4.94 & 2.54 & -2.40 \\
\hline 6 Tlaxcala & -0.87 & 2.78 & 1.89 & -3.28 & -0.76 & 5.53 \\
\hline Total regional & 3.28 & 3.49 & 3.79 & 0.18 & 0.35 & 2.00 \\
\hline \multicolumn{7}{|l|}{ Región 2 Sur Sureste } \\
\hline 1 Campeche & 33.82 & 6.96 & 26.63 & 25.89 & 18.75 & 3.80 \\
\hline 2 Chiapas & 4.69 & 6.87 & 15.09 & 0.56 & 8.55 & 55.47 \\
\hline 3 Guerrero & 5.53 & -0.84 & -0.43 & 9.59 & -0.93 & 7.66 \\
\hline 4 Oaxaca & -2.34 & 9.45 & 14.55 & -11.50 & 6.33 & 23.04 \\
\hline 5 Quintana Roo & 3.58 & 3.47 & 10.83 & -0.83 & 5.55 & 4.77 \\
\hline 6 Tabasco & 26.11 & 1.31 & 48.15 & 29.03 & 47.78 & 32.03 \\
\hline 7 Veracruz & 46.38 & -0.23 & 9.19 & 44.49 & 9.16 & -14.25 \\
\hline 8 Yucatán & 16.01 & 1.74 & 8.69 & 14.72 & 7.56 & -6.34 \\
\hline Total regional & 16.72 & 3.59 & 16.59 & 14.00 & 12.84 & 13.27 \\
\hline \multicolumn{7}{|c|}{ Región 3 Centro Occidente } \\
\hline 1 Aguascalientes & 3.38 & 6.57 & 8.42 & -0.73 & 3.10 & 7.11 \\
\hline 2 Colima & 72.89 & 10.60 & 7.38 & 57.66 & -3.19 & -29.24 \\
\hline 3 Guanajuato & 13.13 & 9.68 & 15.94 & 4.29 & 7.11 & 2.27 \\
\hline 4 Jalisco & 3.57 & 1.14 & 4.07 & 3.01 & 3.29 & 1.57 \\
\hline 5 Michoacán & -11.23 & 1.95 & 6.25 & -12.94 & 4.21 & 20.73 \\
\hline 6 Nayarit & 14.29 & 5.98 & 13.74 & 8.26 & 7.55 & 2.85 \\
\hline 7 Querétaro & 20.33 & 13.01 & 18.91 & 6.81 & 5.36 & 1.87 \\
\hline 8 San Luis PotosI & 23.92 & 4.73 & 13.39 & 19.88 & 9.47 & -8.08 \\
\hline 9 Zacatecas & 41.35 & 3.97 & 8.76 & 36.93 & 5.28 & -22.97 \\
\hline Total regional & 20.18 & 6.40 & 10.76 & 13.68 & 4.69 & -2.66 \\
\hline \multicolumn{7}{|l|}{ Región 4 Noroeste } \\
\hline 1 Baja California & 0.35 & 9.93 & 8.08 & -8.52 & -1.54 & 9.19 \\
\hline 2 Baja Califomia Sur & 27.69 & 11.21 & 19.32 & 9.99 & 3.12 & -5.86 \\
\hline 3 Sinaloa & 5.92 & -0.45 & 3.47 & 7.67 & 4.98 & -1.80 \\
\hline 4 Sonora & 39.40 & 8.95 & 13.82 & 27.88 & 4,43 & -17.75 \\
\hline Total regional & 18.34 & 7.41 & 11.17 & 9.25 & 2.74 & 4.05 \\
\hline \multicolumn{7}{|l|}{ Región 5 Noreste } \\
\hline 1 Chihuahua & 22.13 & 4.39 & 8.96 & 21.40 & 6.40 & -9.63 \\
\hline 2 Coahuila & -11.17 & -2.18 & -2.82 & -9.31 & -0.75 & 9.82 \\
\hline 3 Durango & 12.99 & -0.67 & 4.63 & 15.15 & 7.50 & -7.34 \\
\hline 4 Nuevo León & 13.96 & 8.08 & 4.61 & 6.15 & -2.61 & -8.19 \\
\hline 5 Tamaulipas & 2.66 & -0.26 & 5.76 & 2.79 & 5.90 & 3.36 \\
\hline Tntal remional & 8.12 & 1.87 & 4.23 & 7.24 & 3.29 & -2.40 \\
\hline
\end{tabular}

Fuente: INEGI (2015b). 